\title{
Electoral Competition through Issue Selection
}

\author{
Enriqueta Aragonès ${ }^{1}$ Institut d'Anàlisi Econòmica, CSIC and Barcelona GSE \\ Micael Castanheira ${ }^{2}$ Université Libre de Bruxelles, ECARES and FNRS \\ Marco Giani ${ }^{3}$ Université Libre de Bruxelles, ECARES
}

March 2014. Forthcoming in the American Journal of Political Science

Acknowledgements: acknowledges financial support by the Generalitat de Catalunya Grant number 2009 SGR 1126, the Spanish Ministry of Education grant number ECO2009-08820 and the Barcelona Graduate School of Economics. Castanheira is FNRS research fellow and is grateful for their financial support. We thank the editor of this Journal, Rick Wilson, three anonymous referees, as well as Torun Dewan, Patrick Legros, Andrea Mattozzi, Massimo Morelli, Ken Shepsle, Eric Snowberg, and the audiences at various seminars and workshops for very helpful discussions and comments.

\footnotetext{
${ }^{1}$ Institut d'Anàlisi Econòmica, CSIC, Campus UAB, 08193 Bellaterra (Spain). Email: enriqueta.aragones@iae.csic.es

${ }^{2}$ ULB - ECARES CP 114/04, Avenue Roosevelt, 50, 1050 Bruxelles. Email: mcasta@ulb.ac.be

${ }^{3}$ ULB - ECARES CP 114/04, Avenue Roosevelt, 50, 1050 Bruxelles. Email: mgiani@ulb.ac.be
} 
Abstract: Politics must address multiple problems simultaneously. In an ideal world, political competition would force parties to adopt priorities that reflect the voters' true concerns. In reality, parties can run their campaigns in such a way as to manipulate voters' priorities. This phenomenon, known as priming, may allow parties to underinvest in solving the issues that they intend to mute.

We develop a model of endogenous issue ownership in which two vote-seeking parties (i) invest in policy quality to increase the value of their platform and (ii) choose a communication strategy to prime voters. We identify novel feedbacks between communication and investment. In particular, we find that stronger priming effects can constrain parties to invest more resources in all issues. We also identify the conditions under which parties prefer to focus on their "historical issues" or to engage in "issue stealing".

Keywords: party strategy, salience, issue selection and ownership, priming. JEL codes: D72, H11 
'The critical difference among elections is the problem concern of the voters, not their policy attitudes' A. Petrocik

A central part of a candidate's electoral campaign is to identify key policy issues and advertise how he or she intends to address them if elected. To decide which candidate to vote for, the core of the electorate then evaluates each candidate's proposals, and whether each candidate's main issues accord with their own priorities. As long as the candidates' choice of issues conforms with the voters' sense of priorities, political competition can only benefit voters. However, as voters' priorities are malleable (Smith 1985a, 1985b; Page and Shapiro, 1992), political campaigns can also be expected to aim at manipulating the voters' sense of priorities to the candidate's own advantage. This makes the political process of issue selection in political campaigns far from trivial, ${ }^{4}$ and raises three interlinked questions: (i) How many core campaign issues will candidates select? (ii) What will these issues be? Those important to the voters, or those important to the candidate? (iii) Does the candidates' capacity to manipulate voters' priorities eventually hurt or benefit voters?

Among the research on parties' incentives to select specific issues for their campaigns, the influential work by Riker (1993) identifies the dominance and dispersion principles. The dominance principle states that when one party dominates on a particular issue, it brings it to the fore of its campaign, whereas the other party abandons it. The dispersion principle states that when neither party dominates, both parties abandon the issue. The behavioral prescription of these principles is that each party should emphasize not only its own strengths but also its opponent's

\footnotetext{
${ }^{4}$ Among others, Iyengar et al. (1982, p848) emphasizes that the ability of self-interested players to prime citizens evokes the "sinister possibility" that political elites "might determine what the public takes to be important".
} 
Achilles' heel. Yet, Riker does not identify what allows a party to "dominate" on an issue.

Petrocik's (1996) issue ownership theory fills this gap, associating party dominance with its "reputation for greater competence in handling the issue". A party's reputation for greater competence might stem from better technical expertise to handle the issue or from an ideological bias that makes the party more committed to addressing it. Accordingly, the Democrats should be expected to systematically emphasize issues such as "education" and "healthcare", whereas the Republicans should focus on foreign and security issues, such as "terrorism" or "immigration". While such predictions have been met in several elections, the history of electoral campaigns also abounds with counterexamples. In the US, in the presidential campaign of 2000, Bush turned education and social security into key issues for his campaign, despite them being traditionally Democratic. ${ }^{5}$ Conversely, Clinton managed to turn the issue "criminality" - historically owned by the Republicans- into a major asset for his 1996 presidential campaign. ${ }^{6}$ Moreover, both candidates may mute some issues during a campaign, even though they are important for the voters. Both McCain and Obama muted the issue "illegal immigration" in their presidential campaigns, despite the fact that it was perceived as "important" or "very important" by $60 \%$ of voters in January 2008 (Fortune magazine poll, see pollingreport.com), both Clinton and Bush abandoned the issue "drugs" during their 1992 campaigns

\footnotetext{
${ }^{5}$ Damore (2004) writes that "the 2000 campaign is an outlier that does not comport with my theoretical expectation"; Petrocik et al. (2004) hold that "the 2000 election was an outlier" and, in a similar fashion, Aldrich et al. (2005) state that "the tradition of the issue ownership approach therefore had nothing to say about many of the voters' major concerns in the 2000 election." These facts, reinforced by empirical work on issue ownership (see e.g. Ansolabehere and Iyengar 1994; Sides 2006; Sigelman and Buell 2004; Pope and Wonn 2008; Walgrave et al. 2009) highlight a non negligible degree of instability in the association between party reputation and the choice of issues in electoral campaigns.

${ }^{6}$ Holian (2004, p97) details "how the Clinton campaign and, in turn, the administration turned a long-time Democratic weakness into a non-issue in 1992, and ultimately a rhetorical strength by the 1996 campaign". See also Damore (2004).
} 
even though it was the issue most cited by voters in August 1991 (Washington Post opinion poll, see ropercenter.uconn.edu). ${ }^{7}$

We propose a theory that identifies when and why parties, in accordance with Petrocik's issue ownership theory, choose either to focus on campaign issues for which they have a better reputation, or to engage in issue stealing (aka issue trespassing). We follow Petrocik in letting reputation reflect past actions and past rhetorical arguments, but, importantly, we distinguish between reputation and actual policy proposals. In our setup, reputation determines issue ownership before the campaign starts, but, expanding beyond Petrocik's idea of reputation, we also consider the ability for each party to improve its program. When preparing their programs, parties can invest supplementary resources to develop novel policies and acquire newly built "rhetorical dominance". This ability to invest, we find, may induce parties to end up raising an issue on which they initially were not perceived to be dominant. Our theory thus incorporates the idea that, even if costly, parties can engineer a policy proposal that offsets their initially weak reputation.

Central to our analysis is the parties' ability to prime voters. Priming reflects the capacity of the parties and the press to influence (or even manipulate) the voters' sense of priorities across issues. ${ }^{8}$ A well-understood effect of priming via a political campaign is what we call the attention-shifting effect: by focusing its campaign on a particular issue, a candidate can induce voters to partially ignore the other issues

\footnotetext{
${ }^{7}$ The issue "drugs" being abandoned, it lost importance in opinion polls throughout the 1992 campaign. This pattern prevails in most campaigns: muted issues lose salience, whereas the opposite happens for the main campaign themes - we return to these "priming effects" below.

${ }^{8}$ There is ample evidence that voter priorities can be influenced by party advertisement. The claim that the media may not be successful in telling people what to think, but they are successful in telling them what to think about (Cohen, 1963), first corroborated by McCombs and Shaw (1972), got strong support in a vast experimental and empirical literature in psychology, political psychology and political science (Kahneman and Tversky 1979, 1981, 1984; Iyengar 1990; Iyengar et al. 1982; Iyengar and Kinder 1987; Krosnick and Kinder 1990, Sheafer and Weimann 2005, Bartels 2006. For a critique, see also Lenz 2009).
} 
at the time of voting. We find that such voter malleability induces each party to focus its campaign on one issue only, the one on which it has acquired the strongest dominance. This has three important implications: (1) the core issue chosen by the party need not be the one that voters find the most important. (2) The electoral campaign will address fewer issues than those the electorate actually cares about. In particular, both parties abandon/mute the issues for which the quality gap is the smallest. (3) Whether or not there is issue stealing depends on the parties' relative incentive to invest in each issue.

A party's relative incentive depends on a second and novel effect of priming, which we call the homogenization effect: the better parties become at manipulating voters' priorities, the more homogeneous the electorate becomes. In our model, all voters listen to all campaign advertisements. Through priming, the ads affect voters' priorities in such a way that voters come to perceive as more important those issues discussed by the candidates than those not mentioned during the campaign. Thus, as the electoral campaign progresses, the priorities of the voters not only come to reflect more closely those of the parties, but they also become more similar among voters. This homogenization effect implies that the competition for votes will be tougher at the end of the electoral campaign, because any marginal change in a party's platform quality can produce a large increase in the party's probability of winning. Our results show that, when parties become very good at manipulating voters, they may end up in an 'issue race', in which they must invest massively in all issues. In this case, issue stealing may obtain in equilibrium, which renders issue ownership unstable.

Whether or not there is issue stealing also depends on the strength of the parties' initial reputation. The fact that a party initially owns an issue is not sufficient to 
conclude that the party should campaign on it. What matters is the magnitude of the reputational gap on the issue between the two parties (together with their capacity to prime voters). When the gap is small, the weaker party has a clear incentive to compensate for its initial handicap with higher investments, which might result in issue stealing. Interestingly, this incentive can be reinforced by the inability of the parties to manipulate voters' priorities, and by the voters' valuation of the parties' investment in the issues on which none of the parties dominates.

Finally, we find that parties may end up suffering the costs of their capacity to manipulate voters' priorities, while voters may benefit from being manipulable. Indeed, as explained above, as parties become more skilled at priming voters, interparty competition increases. Parties are forced to invest more in crafting better proposals on some issues, which benefits voters. Yet, parties also underinvest in the issues they intend to abandon. The overall welfare implications of these investment shifts depend on the voters' true valuation of the parties' efforts on each issue.

The rest of the paper proceeds as follows: first, we introduce the model. Then, each section focuses on a different stage of the game, which we solve backwards: we begin by solving for the voting stage, then the communication stage, and finally the policy quality stage. We conclude by suggesting directions for future research. Most proofs are in the appendix.

\section{The Model}

Two office-motivated parties, denoted by $P \in\{A, B\}$, compete for votes in an election. For the sake of tractability, the policy space is restricted to three dimensions: each voter is concerned by up to three issues $k \in\{a, b, c\}$. The electoral game has three stages: (1) each party drafts a platform with proposals for each issue. A 
proposal is identified by its quality, $q_{k}^{P} \geq 0$. The platform of party $P$ is a vector of qualities: $\mathbf{q}^{P} \equiv\left\{q_{a}^{P}, q_{b}^{P}, q_{c}^{P}\right\}$. (2) Given the two parties' platforms, each party decides how much communication time $t_{k}^{P} \geq 0$ to allocate to each issue. ${ }^{9}$ (3) On election day, each voter casts her ballot for the party who proposes the highest weighted average quality. ${ }^{10}$ As detailed below, the weights used to compute average quality are given by each voter's salience weights $s_{k}^{i} \in[0,1]{ }^{11}$

Our setup contrasts with the classical Downsian approach to political competition. In a Downsian context, party choices would be driven by the party's preferences over issues and by the divisiveness of each issue. ${ }^{12}$ We voluntarily abstract from these ideological cleavages to focus on policy innovations. Put differently, we focus on the common value (vertical differentiation) rather than on the ideological divisiveness (horizontal differentiation) dimension of policies (the conclusion discusses how the model could be extended to incorporate ideology). Finally, our setup assumes symmetric information and full commitment: all policy qualities are observable at the election stage and, once elected, a party actually implements the policies developed at stage 1 . In this way, we reduce the gap between pre- and post-electoral considerations. $^{13}$

\footnotetext{
${ }^{9}$ The timing between stages 1 and 2 can be reversed or actions made simultaneous without affecting any of the pure strategy equilibrium results. In a mixed strategy equilibrium, parties would always re-optimize their communication campaign in light of their realized relative performance on each issue, which makes our timing more meaningful.

${ }^{10}$ In a closely related paper, Krasa and Polborn (2010) only consider the investment stage, and abstract from the advertisement stage. They show that equilibrium platform policies diverge, but not enough from a welfare perspective. Conversely, Amorós and Puy (2013) only consider the advertisement stage. They show when parties advertise the same or different issues.

${ }^{11}$ This parametrization builds on Belanger and Meguid's (2008) empirical finding that a voter's decision is more impacted by party ownership in issue $k$, the more importance she gives to the issue in question (p479).

${ }^{12}$ Glazer and Lohmann (1989), and Morelli and Van Weelden (2011 and 2013) consider a framework in which the incumbent can work on ideological issues respectively to close the issue or to signal her type. Krasa and Polborn (2014) study the interaction between the degree of polarization on divisive issues and party proposals on the tax rate. Finally, Aragonès and Sánchez-Pagés (2010) highlight how an incumbent reacts to the emergence of an exogenously important issue.

${ }^{13}$ Demange and Van Der Straeten (2013) propose a model in which voters are imperfectly in-
} 
Stage 1: proposal quality. Both parties simultaneously invest resources to produce policy innovations that increase their proposals' quality on each issue, $q_{k}^{P}(\geq 0) \cdot{ }^{14}$ The investment cost of delivering a proposal of quality $q_{k}^{P}(\geq 0)$ is quadratic in quality and decreasing in the party's reputation on the issue, $\theta_{k}^{P}$ :

$$
C_{k}^{P}\left(q_{k}^{P}\right)=\frac{\left(q_{k}^{P}\right)^{2}}{\theta_{k}^{P}} .
$$

Summing across issues, the total cost of drafting the party manifesto is: $C^{P}\left(\mathbf{q}^{P}\right)=$ $\sum_{k}\left[\left(q_{k}^{P}\right)^{2} / \theta_{k}^{P}\right]$

Party reputation $\theta_{k}^{P}$ reflects among other things the expertise of the party staff and Congressmen accumulated in the past, as in Petrocik (1996). In our model, this expertise increases the party's ability to develop novel proposals that voters will value. However, what matters for the upcoming campaign is not only the past. At the time of the election, voters will compare the quality $q_{k}^{P}$ of the parties' actual proposals (see below). Quality is thus the key variable to determine issue ownership at the end of the campaign. Delivering high quality is costly, but this cost is lower for the party with a better expertise on the issue.

We assume that $\theta_{a}^{A}>\theta_{a}^{B}$ and $\theta_{b}^{A}<\theta_{b}^{B}$ : party $A$ enjoys a reputation advantage à la Petrocik on issue $a$ and party $B$ on issue $b$. We also assume that $\theta_{c}^{A}=\theta_{c}^{B}$ : both parties are equally good at tackling issue $c{ }^{15}$ Throughout, we focus on the symmetric case, in which $\theta \equiv \theta_{a}^{A}=\theta_{b}^{B}>1, \theta_{b}^{A}=\theta_{a}^{B}=1$ and $\theta_{c}^{A}=\theta_{c}^{B}=\theta_{c} \geq 0$. formed, and parties have control on how much information they provide about each issue.

${ }^{14}$ Other models distinguish the incumbent from the challenger, in which case moves are sequential. See for instance Glazer and Lohmann (1999), Soubeyran and Gautier (2008), Morelli and Van Weelden (2011) or Egorov (2012).

${ }^{15}$ Belanger and Meguid (2008, pp482 and 487) find that only $15 \%$ of the voters consider that a same party dominates on all issues. Such voters should be considered as pure partisans, whose voting behavior is not influenced by the mechanisms we identify. Instead, the voting decisions of the remaining $85 \%$ are found to strongly depend on the relationship between party reputation and issue salience. 
Notice that we do not make any assumption on the value of $\theta_{c}$, which can be zero (in which case this issue disappears from the election), larger or smaller than 1, and larger or smaller than $\theta$.

We refer to issue specialization as the case in which the parties' quality provisions mirror their reputation advantages. Issue stealing is the complementary situation:

Definition 1 There is "issue specialization" if $q_{a}^{A} \geq q_{a}^{B}$ and $q_{b}^{A} \leq q_{b}^{B}$ with probability one, given the equilibrium strategy played by the parties. Conversely, there is "issue stealing" if at least one of these inequalities is violated with strictly positive probability.

Stage 2: the communication campaign. Parties allocate their communication time to induce voters to focus more on the issue(s) of their choosing. Let $t_{k}^{P}(\geq 0)$ denote the amount of time (or the value of the advertisements) that party $P$ devotes to campaigning on issue $k$. Throughout the campaign, the total amount of campaigning time devoted to issue $k$ is:

$$
t_{k}=t_{k}^{A}+t_{k}^{B}
$$

Normalizing total campaigning time to 1 and assuming that each party controls half of the total campaigning time, each party's time constraint is: ${ }^{16}$

$$
t^{A} \equiv \sum_{k} t_{k}^{A}=\frac{1}{2}=\sum_{k} t_{k}^{B} \equiv t^{B} .
$$

\footnotetext{
${ }^{16}$ As we show in the supplementary appendix, the model directly extends to endogenous campaigning budgets and advertisement times. When facing identical fundraising opportunities, the outcome is always that the two parties choose the same allocation of spending between quality and advertisement, which implies that $t^{A}=t^{B}$ in equilibrium. Slass $(2001, \mathrm{p} 4)$ for instance illustrates that the Republicans spent $\$ 83.5$ million on issue ads, and the Democrats $\$ 78.4$ million in the 1999-2000 campaign.
} 
The role of the communication campaign is to influence the voters' salience weights. The more parties communicate on issue $k$, the more this issue will weigh on the voters' decision at stage 3 . The process through which communication affects the salience of an issue has been termed priming by political psychologists. In the context of an electoral campaign, priming effects imply that voters attach larger salience to the issues that are emphasized more. ${ }^{17}$ Our contribution in this respect is to offer a tractable functional form for the effects of priming on issue salience, in which the parties' communication strategy influences the salience weights $s_{k}^{i}$, but voters perfectly observe proposal qualities $q_{k}^{i}$.

Formally, prior to the electoral campaign, each voter has initial issue weights $\sigma_{k}^{i}(\geq 0)$, with $\sum_{k} \sigma_{k}^{i}=1$. At the end of the campaign, these weights become:

$$
s_{k}^{i}\left(t_{k}\right)=\beta t_{k}+(1-\beta) \sigma_{k}^{i} .
$$

The salience weight $s_{k}^{i}$ is thus a convex combination of the (party-controlled) campaigning times $t_{k}$, and of the voter's prior weights $\sigma_{k}^{i}$. In that convex combination, $\beta$ is the relative influence of the electoral campaign and $(1-\beta)$ that of the initial weights. The parameter $\beta$ thus captures priming effectiveness, that is the parties' capacity to manipulate voters. ${ }^{18}$ To fix ideas, Bartels (1996) finds that priming can increase issue salience by 40 to $100 \%$. If a voter's initial weights are $\{1 / 3,1 / 3,1 / 3\}$, this yields an estimate of $\beta$ that lies between 0.2 and $0.5 .^{19}$

Stage 3: voting. At the beginning of stage 3, voters observe the quality of all

\footnotetext{
${ }^{17} \mathrm{~A}$ relevant question is whether it is the media or the parties who select the information that the voters will receive. It was shown that the media generally reflect, rather than affect, party agenda (Brandeburg, 2003; Bartels, 1996). Also, there is evidence that priming effects are maximal when, in electoral campaigns, both the parties and the media emphasize the same issues.

${ }^{18}$ One potential microfoundation for such psychological processes could be that voters are imperfectly informed and face inspection costs to assess party proposals.

${ }^{19}$ Solving for $\mu / 3=\beta+(1-\beta) / 3$, when $\mu$ is respectively set to 1.4 and 2 .
} 
party proposals and the communication campaign of the two parties. A voter $i$ is characterized by the salience weight $s_{k}^{i}\left(t_{k}\right)(\geq 0)$ she assigns to issue $k$, with $\sum_{k} s_{k}^{i}\left(t_{k}\right)=1$. To identify which party she will support, voter $i$ compares the relative merits of each party's proposal on each issue. She votes for party $A$ iff:

$$
\begin{aligned}
& \sum_{k} s_{k}^{i}\left(t_{k}\right) q_{k}^{A} \geq \sum_{k} s_{k}^{i}\left(t_{k}\right) q_{k}^{B}, \text { or } \\
& \sum_{k} s_{k}^{i}\left(t_{k}\right) \Delta_{k} \geq 0, \text { with } \Delta_{k} \equiv q_{k}^{A}-q_{k}^{B},
\end{aligned}
$$

where $\Delta_{k}$ is $A$ 's quality advantage on issue $k$. Importantly, note that within each issue all voters value quality in the same way.

Party objectives and voter distribution. Each party thus has six control variables (three quality choices and three campaigning time choices) to maximize its probability of winning net of investment costs:

$$
\Pi^{P}(\mathbf{q}, \mathbf{t})=\pi^{P}(\mathbf{q}, \mathbf{t})-C^{P}(\mathbf{q})
$$

where $\mathbf{q} \equiv\left\{q_{a}^{A}, q_{b}^{A}, q_{c}^{A}, q_{a}^{B}, q_{b}^{B}, q_{c}^{B}\right\}$ and $\mathbf{t} \equiv\left\{t_{a}, t_{b}, t_{c}\right\}$. Party $A$ wins if the pivotal voter, given her posterior salience weights $s_{k}\left(t_{k}\right)$, prefers the manifesto of $A$ to that of $B .^{20}$ Given a distribution $f$ of the pivotal voter's salience weights, this happens with probability (from now on, we drop the variable $t_{k}$ from $s_{k}\left(t_{k}\right)$ for the sake of

\footnotetext{
${ }^{20}$ We could use two interpretations that are mathematically equivalent. Either one based on a winner-takes-it-all system where the distribution of the pivotal voter's salience weights is understood as random. Alternatively, one may consider a proportional representation system, in which case we can assume away aggregate uncertainty, and $f$ denotes the overall distribution of salience weights across the electorate. In the paper, we follow the former interpretation.
} 


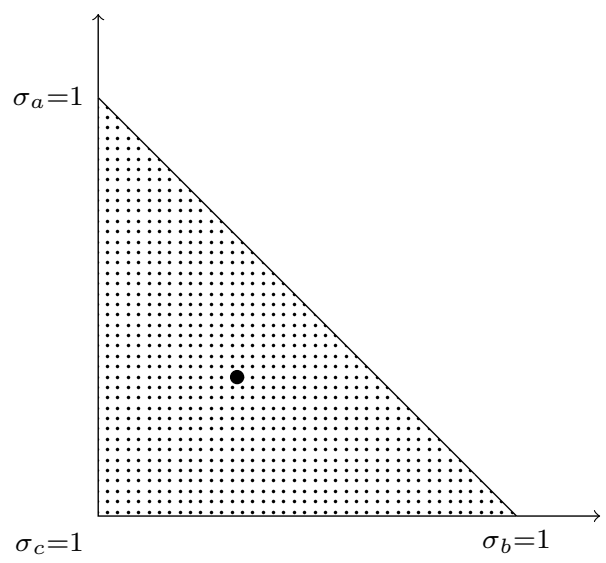

Figure 1: Ex-ante distribution of the pivotal voter's salience weights. The expected location of the pivotal voter is given by the intersection between all the barycentric coordinates of the simplex.

readability):

$$
\pi^{A}(\mathbf{q}, \mathbf{t})=\int_{s_{a}} \int_{s_{b}} 1\left[\sum_{k} s_{k} \Delta_{k} \geq 0\right] f\left(s_{a}, s_{b}, s_{c}\right) d s_{b} d s_{a}, \text { s.t. } s_{c}=1-s_{a}-s_{b} .
$$

The indicator function $1\left[\sum_{k} s_{k} \Delta_{k} \geq 0\right]$ has value 1 when the pivotal voter prefers $A$ to $B$ in (2) and 0 otherwise.

We assume a uniform distribution of the pivotal voter's ex-ante salience weights over the simplex of admissible preferences:

$$
S_{\sigma} \equiv\left\{\left(\sigma_{a}, \sigma_{b}, \sigma_{c}\right): \sigma_{k} \geq 0, \sum_{k} \sigma_{k}=1\right\}
$$

The density of ex-ante weights within that simplex is therefore: $f_{\sigma}\left(\sigma_{a}, \sigma_{b}, \sigma_{c}\right)=2$, $\forall\left(\sigma_{a}, \sigma_{b}, \sigma_{c}\right) \in S_{\sigma}$. Figure 1 illustrates this graphically.

However, as explained above, voters are primed by the parties' communication campaign (see (1)). From (5), one can derive the set of admissible final salience 


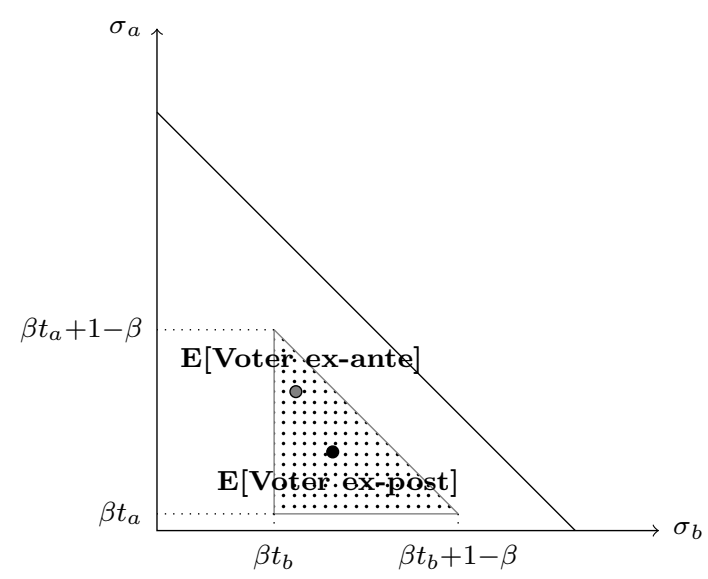

Figure 2: Ex-post distribution of the pivotal voter's salience weights: the expected location changes and the simplex shrinks.

weights, $S_{s}(\mathbf{t}, \beta)$ :

$$
S_{s}(\mathbf{t}, \beta) \equiv\left\{\left(s_{a}, s_{b}, s_{c}\right): \beta t_{k} \leq s_{k} \leq \beta t_{k}+1-\beta, k=a, b, c\right\}
$$

which is a smaller triangle within the unit simplex. The size of this triangle is smaller the larger is $\beta$. In other words, a consequence of more effective priming (higher $\beta$ ) is to reduce the uncertainty surrounding the set of admissible salience weights. This is illustrated in Figure 2.

At the time of the election, the density of the pivotal voter's weights has thus increased to $f_{s}\left(s_{a}, s_{b}, s_{c}\right)=\frac{2}{(1-\beta)^{2}}$, over a smaller set $S_{s}(\mathbf{t}, \beta)$.

Equilibrium concept. We focus on the subgame perfect equilibria of this game: at stage 3, voters cast their ballot on the party that maximizes their utility, given salience weights $s_{k}^{i}$. The winning party is the one preferred by the pivotal voter. At stage 2, each party chooses the communication strategy that maximizes its probability of winning given the vector of qualities realized at stage 1. At stage 1, parties choose the vector of qualities that maximize (3) given expected advertisement strat- 
egy at stage 2 and voting behavior at stage 3 .

\section{The Voting Stage}

Given the voters' decision rule (2), we can compute the winning probabilities of each party at stage 3 . These depend on the parties' proposal qualities. There are three cases to consider: in case $\mathbf{A}$, party $A$ dominates $B$ in all issues. In case $\mathbf{B}, B$ dominates. In case $\mathbf{U}$, for Undominated, none of the parties dominates in all issues.

Case A. Party $A$ proposes a higher quality on all issues:

$$
\Delta_{k} \geq 0, \forall k \text { with at least one strict inequality. }
$$

In that case, all voters prefer $A$ to $B$ and $A$ 's winning probability is 1 independently of the parties' communication strategies. Further increases of proposal quality by party $A$ cannot further increase $A$ 's winning probability.

Case B. Party $A$ proposes a lower quality on all issues:

$$
\Delta_{k} \leq 0, \forall k \text { with at least one strict inequality. }
$$

In that case, all voters prefer $B$ to $A$ and $A$ 's winning probability is 0 . In this case as well, the communication strategy has no effect.

Case U. None of the parties proposes higher quality on all issues:

$$
\min _{k} \Delta_{k}<0<\max _{k} \Delta_{k}
$$

In that case, a voter who assigns salience weight 1 to the former issue strictly prefers 
$B$ to $A$, and conversely for a voter who assigns weight 1 to the latter issue.

Let us focus for the time being on the most intuitive situation, in which $A$ 's quality advantage is positive and strongest in $a$, and that of $B$ is positive and strongest in $b$ : $\Delta_{a}>0, \Delta_{b}<0, \Delta_{c} \in\left[\Delta_{b}, \Delta_{a}\right]$. By (2), voter $i$ prefers $A$ to $B$ if, given her weighting of issues $s_{k}^{i}$, she prefers $A$ 's platform: $\sum_{k} s_{k}^{i} \Delta_{k} \geq 0$. These are the voters who value issue $a$ sufficiently more than issue $b$. Indeed, exploiting the fact that $\sum_{k} s_{k}^{i}=1,(2)$ can be re-written as:

$$
s_{a}^{i}\left[\Delta_{a}-\Delta_{c}\right]+s_{b}^{i}\left[\Delta_{b}-\Delta_{c}\right]+\Delta_{c} \geq 0 .
$$

The voters who vote for $A$ at stage 3 are therefore:

$$
\left\{i: s_{a}^{i} \geq s_{b}^{i} \frac{\Delta_{c}-\Delta_{b}}{\Delta_{a}-\Delta_{c}}-\frac{\Delta_{c}}{\Delta_{a}-\Delta_{c}}\right\} .
$$

In other words, $A$ and $B$ voters are separated by a cutoff line. Importantly, parties can both influence the position of this cutoff line - by varying their qualities- and the distribution of the voters's salience weights -by varying their advertisement times:

1. higher policy quality by party $A$ and lower policy quality by party $B$ always enlarges the set (6) by moving the cutoff line "down" and "right" in Figure 3. Yet, policy quality cannot affect the distribution of issue weights.

2. increasing the share of campaigning time dedicated to communicating about issue $a$ rather than issue $b$ moves the distribution of salience weights "up" and "left" in Figure 4a. Figures 4b and c illustrate the effects of more communication time on issues $b$ and $c$ respectively. In contrast with policy quality, communication cannot affect the position of the cutoff line. 


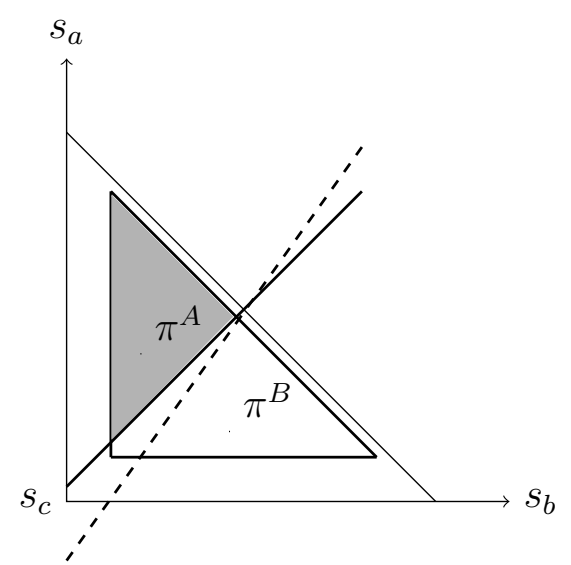

(a) $\Delta_{c}$ increases

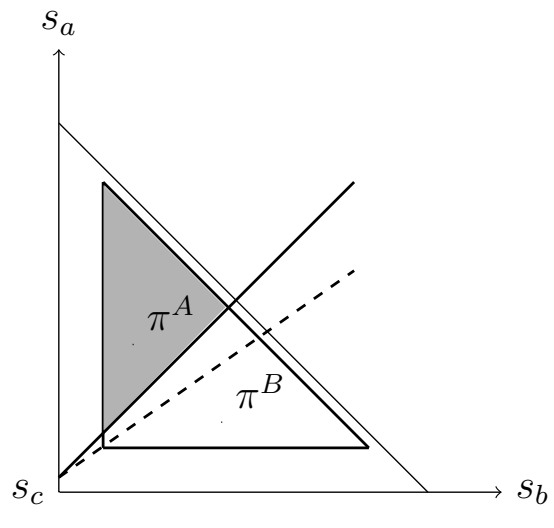

(b) $\Delta_{b}$ increases

Figure 3: The solid line, depicted for $\Delta_{a}=-\Delta_{b}$ and $\Delta_{c}=-0.1$, determines the winning probability of party $A$ and $B$. On panel $a$, the dashed line describes the effect of an increase in $\Delta_{c}$. On panel $b$, the dashed line describes the effect of an increase in $\Delta_{b}$.

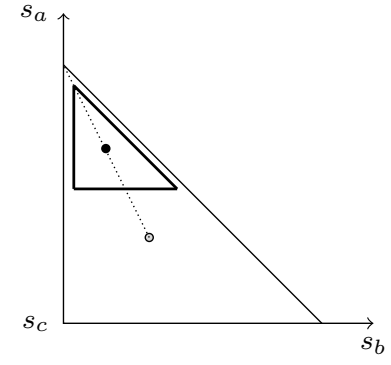

(a) Issue $a$

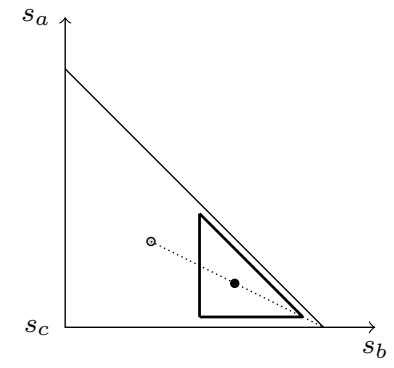

(b) Issue $b$

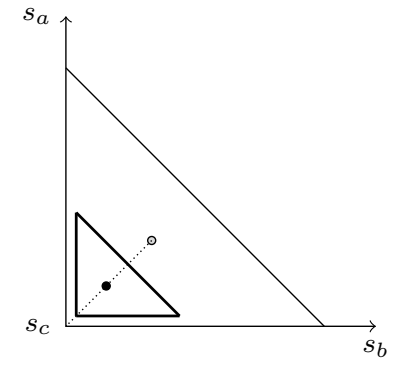

(c) Issue $c$

Figure 4: Panel $a, b$ and $c$ shows the change in voters' salience weights distribution. The black(gray) point identifies the expected location of the pivotal voter after(before) the communication stage. 
Combining these two effects, $A$ 's winning probability can be computed as:

$$
\pi^{A}=\int_{s_{a}=s_{b} \frac{\Delta_{c}-\Delta_{b}}{\Delta_{a}-\Delta_{c}}-\frac{\Delta_{c}}{\Delta_{a}-\Delta_{c}}}^{s_{a}=1} \int_{s_{b}=0}^{s_{b}=1} f_{s}\left(s_{a}, s_{b}\right) d s_{b} d s_{a}
$$

where $f_{s}\left(s_{a}, s_{b}\right)=\frac{2}{(1-\beta)^{2}}$ for all $s_{a} \in\left[\beta t_{a}, \beta t_{a}+1-\beta\right]$ and $s_{b} \in\left[\beta t_{b}, \beta t_{b}+1-\beta\right]$, $s_{c}=1-s_{a}-s_{b}$, and $f_{s}\left(s_{a}, s_{b}\right)=0$ otherwise.

Remark 1 If they invest the same (strictly positive) amount in each issue, parties maintain their initial advantage. On issue a for instance, party A delivers strictly higher policy quality than B if both invest the same amount in that issue. Conversely, a party must invest strictly more resources than its competitor to "steal" an issue.

Remark 2 The voters who support party A in (6) would actually turn to supporting party $B$ if quality differentials were reversed: the zones $A$ and $B$ in Figure 3 would be swapped. Expressed differently, if salience weights can be interpreted as the voters' proximity to parties, the base for a party actually depends on the proposals set out by each party in each issue.

\section{The Communication Stage}

At stage 2, investment costs are already sunk. Parties observe qualities and choose a vector of campaigning times $t_{k}^{P}$ : they "prime" voters. Since investment costs are already sunk, they exclusively focus on their winning probability (results extend directly to the case in which parties must allocate an endogenous advertising budget across issues - see supplementary appendix). Here, we focus on the problem of party $A$ in Case $\mathbf{U}$ defined above: in the other cases, communication does not affect vote shares. The analysis is symmetric for party $B$. 
Since $t^{A}=t^{B}=1 / 2$, voters will be exposed to as many arguments from party $A$ as from party $B$. Consider the problem of party $A$ : it chooses a vector $\mathbf{t}^{A}(\mathbf{q}) \equiv$ $\left\{t_{a}^{A}, t_{b}^{A}, t_{c}^{A}\right\}$ to maximize the winning probability given $(i)$ the vector qualities $\mathbf{q}$ resulting from stage 1 and (ii) the communication time constraint, $\sum_{k} t_{k}^{A}=1 / 2$. That is,

$$
\begin{aligned}
\mathbf{t}^{A}(\mathbf{q}) & =\arg \max _{\mathbf{t}^{A}} \pi^{A}\left(\mathbf{q}, t^{A}, t^{B}\right) \\
& \text { s.t. } t_{k}^{A} \geq 0 \text { and } \sum_{k} t_{k}^{A} \leq 1 / 2 \text { for } k \in\{a, b, c\} .
\end{aligned}
$$

Remember that the communication strategy is meant to attract the voters' attention towards specific issue(s) - see (1). It is straightforward to check that each party maximizes its winning probability by concentrating all its campaigning time on a single issue, the one in which its quality advantage is maximal:

Proposition 1 Suppose we are in Case U. Then, for any $\beta$, each party concentrates all its campaigning time on the issue in which it has the largest quality advantage. That is:

$$
\begin{gathered}
\left(t_{a}^{A}(\mathbf{q}), t_{b}^{A}(\mathbf{q}), t_{c}^{A}(\mathbf{q})\right)=\left\{\begin{array}{lll}
(1 / 2,0,0) & \text { if } & \Delta_{a}>\Delta_{c}>\Delta_{b} \text { or } \Delta_{a}<\Delta_{c}<\Delta_{b} \\
(1 / 2,0,0) & \text { if } & \Delta_{a}>\Delta_{b}>\Delta_{c} \text { or } \Delta_{a}<\Delta_{b}<\Delta_{c} \\
(0,0,1 / 2) & \text { if } & \Delta_{b}>\Delta_{a}>\Delta_{c} \text { or } \Delta_{b}<\Delta_{a}<\Delta_{c}
\end{array}\right. \\
\left(t_{a}^{B}(\mathbf{q}), t_{b}^{B}(\mathbf{q}), t_{c}^{B}(\mathbf{q})\right)=\left\{\begin{array}{lll}
(0,1 / 2,0) & \text { if } & \Delta_{a}>\Delta_{c}>\Delta_{b} \text { or } \Delta_{a}<\Delta_{c}<\Delta_{b} \\
(0,0,1 / 2) & \text { if } & \Delta_{a}>\Delta_{b}>\Delta_{c} \text { or } \Delta_{a}<\Delta_{b}<\Delta_{c} \\
(0,1 / 2,0) & \text { if } & \Delta_{b}>\Delta_{a}>\Delta_{c} \text { or } \Delta_{b}<\Delta_{a}<\Delta_{c}
\end{array}\right.
\end{gathered}
$$


And the overall campaign advertisements are:

$$
\left(t_{a}(\mathbf{q}), t_{b}(\mathbf{q}), t_{c}(\mathbf{q})\right)=\left\{\begin{array}{lll}
(1 / 2,1 / 2,0) & \text { if } & \Delta_{a}>\Delta_{c}>\Delta_{b} \text { or } \Delta_{a}<\Delta_{c}<\Delta_{b} \\
(1 / 2,0,1 / 2) & \text { if } & \Delta_{a}>\Delta_{b}>\Delta_{c} \text { or } \Delta_{a}<\Delta_{b}<\Delta_{c} \\
(0,1 / 2,1 / 2) & \text { if } & \Delta_{b}>\Delta_{a}>\Delta_{c} \text { or } \Delta_{b}<\Delta_{a}<\Delta_{c}
\end{array}\right.
$$

where $\Delta_{k} \equiv q_{k}^{A}-q_{k}^{B}$ for $k \in\{a, b, c\}$

To illustrate this result imagine first that both $A$ and $B$ invested the same amount $\bar{C}$ in all three issues, which implies that $A$ (respectively $B$ ) has higher quality on $a$ (respectively $b$ ): $q_{a}^{A}>q_{a}^{B}$ and $q_{b}^{B}>q_{b}^{A}$. This also implies that they tie on issue $c$ : $q_{c}^{A}=q_{c}^{B}$. Expressed in terms of quality differentials, we have: $\Delta_{a}>0=\Delta_{c}>\Delta_{b}$. From the first line in (8), party $A$ only wants to communicate on issue $a$, and party $B$ only on issue $b$. None of the parties brings up $c$, simply because both of them can attract more votes by emphasizing another issue.

Good illustrations of this case might be the US presidential campaigns of 1992 and 2008: in both campaigns, the Democratic candidate campaigned on domestic issues (Clinton emphasized his proposals for a new covenant to America and for reducing the gap between rich and poor; Obama campaigned on his plans for a better social safety net) whereas both Republican candidates Bush and McCain campaigned on foreign issues (their higher ability to combat foreign threats). ${ }^{21}$ In parallel, a historically relevant campaign issue was muted during these campaigns: drugs in 1992 and immigration in 2008. In both cases, the reason for muting this

\footnotetext{
${ }^{21}$ Note that this campaigning pattern does not depend on the absolute advantage of each candidate: imagine that $A$ increases its investment on $a$ in the first stage. Then, emphasizing $a$ in the second stage has a larger impact on its winning probability. But this does not affect its best response: it should still focus the communication campaign on issue $a$. Coming back to the electoral campaign of 1992, Bush kept campaigning on his higher ability to fight foreign threats, even when it was becoming increasingly clear that his success in the Gulf war would be insufficient to win the election.
} 
issue is that none of the candidates could build a strong enough quality advantage on it before the election. Beyond such anecdotal evidence, Damore (2004) shows that neutral issues typically represent between 0 and $2 \%$ of the total campaigning time.

Conversely, imagine that $A$ invested enough on $b$ to steal this issue from $B$ : $\Delta_{b}>0$. The ranking of quality differentials is now $\Delta_{a}>\Delta_{b}>\Delta_{c}=0$. In this case, $A$ still communicates on $a$, since this is its strongest issue, but $B$ 's best response is modified: it should communicate only about issue $c$, since it is now its best option to contain vote losses. This is the second line in (8). One concrete campaign can illustrate this case: President Clinton had built a strong reputation on policies such as social security, education and healthcare. Yet, the Republicans reacted by drafting new proposals to address such issues. In particular, concerning social security, they proposed to allow people to put a portion of their SS payroll taxes into personal retirement accounts that would be invested in private stocks and bonds. This proposal allowed the Republicans to recover dominance in this issue (According to Gallup polls, only 35\% of respondents said Republicans were better able to handle social security in February 1999. This percentage had increased to $65 \%$ at the time of the campaign). In line with Proposition 1, Democrats drastically reduced their communication on social security: while it was central to their 1996 campaign (Iyengar and Valentino 2000, p116), only 25\% of social security ads were aired by the Democrats during the 2000 campaign (Falk 2001, p23).

Considering each possible (set of) case(s), and discarding the non-generic outcomes in which $\Delta$ is equal across two or more issues, shows that only the three communication outcomes of Proposition 1 may emerge. Which is this issue depends on the parties' relative qualities, which in turn depend on both the parties' compar- 
ative advantages and the amount each party has invested in each issue. This result contrasts with the literature, which assumes that parties cannot control how much they invest in each issue. In that case, only history and past reputation may define a party' strong and weak issues in the current election. In our model instead, policy quality and issue ownership are endogenous. The equilibrium outcomes in terms of policy quality are analyzed in the next section.

\section{The Quality Stage}

We can now check how parties prepare their manifestos in anticipation of the campaign: we turn to the first stage of the game, in which parties simultaneously select how much they invest in policy innovations to increase their platform quality.

There are up to three cases to consider: Case $\mathbf{A}$ is when $\Delta_{k}>0, \forall k$. In this case, $A$ 's winning probability is $1 .^{22}$ Case $\mathbf{B}$ is when $\Delta_{k}<0, \forall k$, and $A$ 's winning probability is $0 .{ }^{23}$ Case $\mathbf{U}$ is when none of the parties dominates on all issues, and their winning probabilities take some value between 0 and 1 . We focus on Case $\mathbf{U}$ for the time being, and show that it yields a unique potential equilibrium in pure strategies. Cases A and $\mathbf{B}$ represent possible deviations. They are analyzed in the next sections, where we also analyze the equilibrium in mixed strategies.

In Case $\mathbf{U}$, there is at least one issue $k$ in which $A$ proposes a strictly better policy than $B$ (that is: $\Delta_{k}>0$ ) and at least one issue $k^{\prime}$ in which $B$ 's proposals are better than $A^{\prime}$ s (that is: $\Delta_{k^{\prime}}<0$ ). We focus for now on the intuitive case in which $A$ 's quality advantage is positive and highest in $a$, and that of $B$ is positive

\footnotetext{
${ }^{22}$ Since party $A$ wins with probability 1 for any communication strategy, the latter becomes irrelevant for this part of the analysis. The same holds in Case B.

${ }^{23}$ Notice that Case A and Case B imply issue stealing, but that issue stealing may occur even when a party does not dominate on all issues.
} 
and highest in $b: \Delta_{a}>0>\Delta_{b}$ and $\Delta_{a}>\Delta_{c}>\Delta_{b}$. We only detail the problem of party $A$ : the analysis is symmetric for party $B$.

Party $A$ chooses the vector of policy qualities that maximize its objective function (3) given the anticipated equilibrium communication strategy of stage $2, t_{k}(\mathbf{q})$, as identified in Proposition 1, and the voting behavior (7) that results. That is, it chooses a vector $\mathbf{q}^{A} \equiv\left\{q_{a}^{A}, q_{b}^{A}, q_{c}^{A}\right\}$ such that:

$$
\begin{aligned}
& \mathbf{q}^{A}=\arg \max _{q_{a}^{A}, q_{b}^{A}, q_{c}^{A}} \pi^{A}\left(\mathbf{q}^{A}, \mathbf{q}^{B} ; t_{a}(\mathbf{q}), t_{b}(\mathbf{q}), t_{c}(\mathbf{q})\right)-\sum\left(q_{k}^{A}\right)^{2} / \theta_{k}^{A} \\
& \text { s.t. } q_{k}^{A} \geq 0 \text { for } k \in\{a, b, c\} .
\end{aligned}
$$

This maximization problem is potentially intricate since the party must take into account how first-period quality choices influence the second-period allocation of campaigning times. Yet, the nature of the best responses at the second stage simplifies this problem: the values $t_{k}$ were shown to be constant within each of the three cases identified in Proposition 1. We can thus focus on the simpler problem:

$$
\begin{aligned}
& \mathbf{q}^{A}=\arg \max _{q_{a}^{A}, q_{b}^{A}, q_{c}^{A}} \pi^{A}\left(\mathbf{q}^{A}, \mathbf{q}^{B} ; \mathbf{t}\right)-\sum\left(q_{k}^{A}\right)^{2} / \theta_{k}^{A} \\
& \text { s.t. } q_{k}^{A} \geq 0 \text { for } k \in\{a, b, c\},
\end{aligned}
$$

in which advertisement times $\mathbf{t}$ are independent of $\mathbf{q}$. Once the equilibrium quality choices from stage 1 are identified, we shall identify which case(s) in (8) can actually materialize in equilibrium.

As already detailed, $A$ 's probability of winning is the probability that, given her weighting of the three issues, the pivotal voter values $A$ 's set of proposals more than $B$ 's: $\sum_{k} s_{k} \Delta_{k} \geq 0$, where $\Delta_{k}$ denotes the quality differential in issue $k$, see (7). This 
implies that a marginal increase in quality by party $A$ or by party $B$ have exactly opposite effects on the parties' electoral performance. Hence, the two parties face equal marginal benefits of quality provision.

The difference between the parties only stems from their different marginal costs, which depend on their reputation advantage. The next proposition shows that, whenever a pure strategy equilibrium exists, party $A$ must propose higher-quality policies than party $B$ in issue $a$ and conversely in issue $b$ :

Proposition 2 In a pure strategy equilibrium we must have that $q_{a}^{A}=\theta q_{a}^{B}, q_{b}^{B}=$ $\theta q_{b}^{A}$ and $q_{c}^{A}=q_{c}^{B}$. Therefore,

$$
\Delta_{a}=(\theta-1) q_{a}^{B}>\Delta_{c}=0>(1-\theta) q_{b}^{A}=\Delta_{b}
$$

By Proposition 1 this also implies that, in a pure strategy equilibrium, party $A$ wants to allocate all its campaigning time on issue $a$ and party $B$ on issue $b$ :

$$
\mathbf{t}^{*}=\left(t_{a}, t_{b}, t_{c}\right)=(1 / 2,1 / 2,0)
$$

To derive the exact equilibrium quality levels, we must identify the effects of the communication stage on quality provision. As shown in Figure 2, priming affects salience weights in two different ways: first, the voters' attention moves towards the issues chosen by the parties. Second, voting weights become more homogeneous across voters. We discuss the impact of each of these effects on quality in the following section. 


\section{The Homogenization and Attention-Shifting Effects}

Since issue $c$ is muted at the communication stage, the salience of that issue is reduced. In contrast, the salience of the other two issues, $a$ and $b$, is increased. We shall see that this effect induces parties to soften competition on the neutral issue, which increases their rents. We call this phenomenon the attention-shifting effect of the campaign. This is exactly the parties' purpose: parties want voters to focus on their main strengths $(a$ or $b)$ and disregard their weaknesses $(c)$. Thus the attentionshifting effect induces each party to increase investment on the issue he owns and decrease investment on the neutral issue.

On the other hand, there is a second, unintended, consequence of the campaign. We call it the homogenization effect of the campaign. As the campaign evolves, and because of priming at the second stage, the support of the distribution of the pivotal voter becomes smaller. As a result, a marginal quality increase in any issue has a larger impact on the party's chances of winning the election. This makes competition tougher in all issues. Thus the homogenization effect induces each party to increase investment on all issues. Lemma 1 isolates the homogenization effect of quality provision by considering the out-of-equilibrium campaign in which all issues are emphasized equally.

Lemma 1 For an exogenously set communication campaign $\mathbf{t}=\left\{\frac{1}{3}, \frac{1}{3}, \frac{1}{3}\right\}$, all equilibrium qualities are monotonically increasing in priming effectiveness, $\beta$.

Thus, the more parties can prime voters, the stiffer competition becomes, yielding higher-quality proposals in all issues. Yet, in equilibrium, only issues $a$ and $b$ are emphasized, which triggers the attention-shifting effect. This further increases the parties' incentives to provide high-quality proposals in issues $a$ and $b$, but reduces incentives in issue $c$. Together, the attention-shifting and homogenization effects have 
a clear impact on quality provision for the owned issues $a$ and $b$, but an ambiguous impact on quality provision for the neutral issue, $c$.

How do these two effects eventually shape quality provision in the first stage? Together, Proposition 3 and Corollary 1 show that the attention-shifting effect dominates the homogenization effect on issue $c$ :

Proposition 3 There is a unique potential pure strategy equilibrium (PSE), in which quality levels are:

$$
\begin{aligned}
& q_{a}^{A, P S E}=q_{b}^{B, P S E}=\theta \sqrt{\frac{1}{8(\theta-1)} \frac{1+\beta}{1-\beta}} \\
& q_{a}^{B, P S E}=q_{b}^{A, P S E}=\sqrt{\frac{1}{8(\theta-1) \frac{1+\beta}{1-\beta}}} \\
& q_{c}^{A, P S E}=q_{c}^{B, P S E}=\theta_{c} \sqrt{\frac{1}{2(\theta-1)} \frac{1-\beta}{1+\beta}} .
\end{aligned}
$$

A PSE is thus necessarily symmetric, and such that all quality levels are strictly positive, unless $\theta_{c}=0$.

Hence, there is a unique and symmetric potential pure strategy equilibrium, which necessarily yields to Case U. As detailed above, this implies issue specialization. On top of this, Proposition 3 also allows us to assess the intensity of the parties' ownership of "their" in such an equilibrium. Indeed, the equilibrium quality differentials turn out to be:

$$
\Delta_{a}=\left|\Delta_{b}\right|=\sqrt{\frac{(\theta-1)}{8} \frac{1+\beta}{1-\beta}},
$$

which are monotonously increasing both in the party's reputation advantage $\theta$ and in the effectiveness of priming, $\beta$. The following corollary identifies other interesting 
comparative statics:

Corollary 1 In a symmetric pure strategy equilibrium:

(i) the attention-shifting effect dominates the homogenization effect in the neutral issue $c\left(q_{c}^{P}\right.$ is strictly decreasing in $\left.\beta\right)$,

(ii) the more effective is priming, the higher is equilibrium quality both in the strong and in the weak issue ( $q_{a}^{P}$ and $q_{b}^{P}$ are strictly increasing in $\beta$ ),

(iii) the better parties are at dealing with issue $c$, the higher is platform quality in that issue, without producing an advantage in equilibrium $\left(q_{c}^{P}\right.$ is increasing in $\theta_{c}$ but $\left.\Delta_{c}=0\right)$,

(iv) the parties' reputational advantage has an ambiguous effect on the parties' quality provision in their strong issue, and a negative effect on the other issues.

Let us detail the last effect identified in Corollary 1: from Proposition 3, it is immediate to see that stronger reputation advantages (higher $\theta$ ) reduce quality provision in both a party's "weak" and "neutral" issues: $q_{b}^{A, P S E}$ and $q_{c}^{A, P S E}$ are strictly decreasing in $\theta$. On the other hand, the effect on a party's strong issue is ambiguous. When $\theta$ is close to one (comparative advantages are small), competition is very stiff, since the two parties are almost interchangeable. Slightly increasing $\theta$, parties invest less in all three issues: competition is softened at the expense of voters. But when $\theta$ becomes sufficiently large (larger than 2 in Figure 5), each party can actually provide higher quality policies at comparatively low cost. In that case, quality provision is increasing in $\theta$. The following figure illustrates these effects for $\beta=1 / 3$ and $\theta_{c}=0.5$.

Another interesting implication of Proposition 3 and Corollary 1 is that voter welfare may well be increasing in priming effectiveness. Indeed, welfare is increasing in platform quality, and we just saw that priming effectiveness drives a quality 


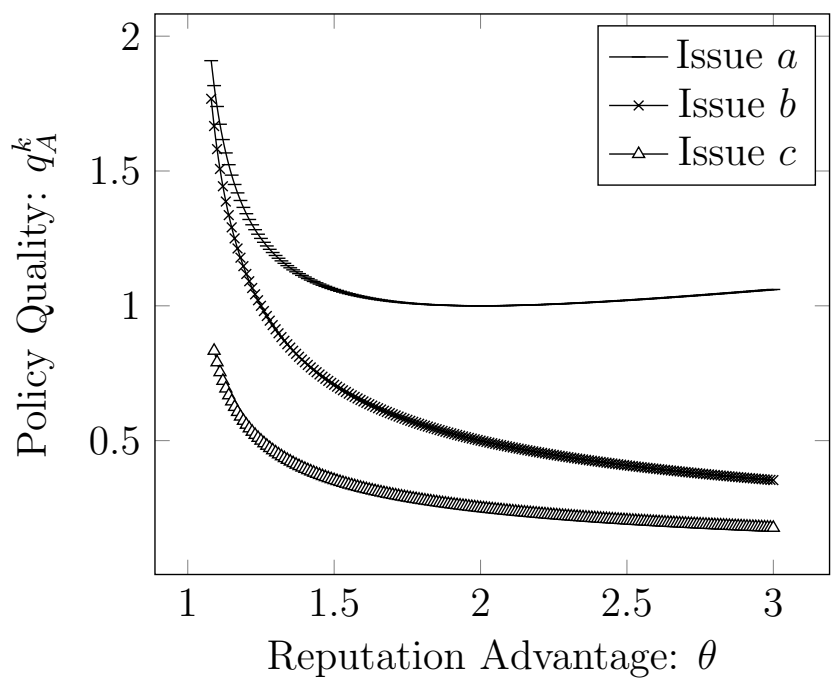

Figure 5: Policy Quality provided by party $A$ 's in all issues as a function of $\theta$, holding $\beta=\frac{1}{3}$ and $\theta_{c}=\frac{1}{2}$.

increase in issues $a$ and $b$ by both parties. Yet, a complete welfare analysis is beyond the scope of our analysis: voter payoffs are indeed endogenous to the campaign, because priming influences salience weights. This makes it impossible to identify the exact welfare function after the campaign, when priming effects may partially fade out. Still, there is a case in which the welfare analysis is unambiguous: when the neutral issue has little importance $\left(\theta_{c}\right.$ is small), policy quality is necessarily low in that issue, and overall qualities must therefore be strictly increasing in priming effectiveness.

\section{Issue Stealing}

The above shows that there is a unique potential pure strategy equilibrium. Yet, to check whether these strategies are indeed an equilibrium, we must consider two additional deviations. We focus on party $A$ : first, it may be tempted to steal all issues from party $B$ and deviate towards Case A. Second, party $A$ may wish to 
deviate by cutting down investment in all issues, and reach Case B. A necessary condition for the potential equilibrium of Proposition 3 to exist is therefore that it provides higher payoffs than any of these two deviations.

Lemmas 2 and 3 in the Appendix establish that we only need to consider exactly one potential deviation towards each case: either party $A$ proposes slightly higher quality levels than what party $B$ provides in the pure strategy equilibrium, or it provides 0-qualities for all issues. We denote the quality levels in the first case with a superscript IS, for Issue Stealing: party $A$ then dominates party $B$ in all issues. We denote the quality levels in the latter case by the vector $\mathbf{q}^{A}=\mathbf{0}$. The quality levels in the potential pure strategy equilibrium are denoted $\mathbf{q}^{A, P S E}$ and $\mathbf{q}^{B, P S E}$, and we define $\mathbf{q}^{P S E} \equiv\left\{\mathbf{q}^{A, P S E}, \mathbf{q}^{B, P S E}\right\}$.

In this section, we focus on the incentive of party $A$ to engage in issue stealing, and pick qualities $\mathbf{q}^{A, I S}$. The payoff of party $A$ when it plays along the strategy derived in Proposition 3 is:

$$
\begin{aligned}
\Pi^{P}\left(\mathbf{q}^{P S E}, \mathbf{t}\right) & =\pi^{A}\left(\mathbf{q}^{P S E}, \mathbf{t}\right)-\sum_{k} \frac{\left(q_{k}^{P, P S E}\right)^{2}}{\theta_{k}^{P}} \\
& =\frac{1}{2}-\frac{1+\beta}{1-\beta} \frac{\theta+1}{8(\theta-1)}-\frac{1-\beta}{1+\beta} \frac{\theta_{c}}{2(\theta-1)} .
\end{aligned}
$$

Conversely, the payoff of party $A$ when it deviates to $\mathbf{q}^{A, I S}$ is:

$$
\Pi^{A}\left(\mathbf{q}^{A, I S}, \mathbf{q}^{B, P S E}\right)=1-\left(\frac{1+\beta}{1-\beta} \frac{1}{8(\theta-1)}\right) \frac{1+\theta^{3}}{\theta}-\frac{1-\beta}{1+\beta} \frac{\theta_{c}}{2(\theta-1)}
$$

Note that the probability of election is $1 / 2$ in the former case, and 1 in the latter. The No issue stealing condition identifies when the former payoff is at least as large as the latter: 
Proposition 4 (No Issue Stealing Condition - NISC) A necessary condition for the existence of a pure strategy equilibrium is that the parties' reputation advantage $\theta$ be sufficiently large and/or that priming is sufficiently effective ( $\beta$ large):

$$
\frac{\theta^{2}-1}{4 \theta} \geq \frac{1-\beta}{1+\beta}
$$

Proof. Immediate from (9) and (10).

When condition (11) is not satisfied, e.g. because parties are insufficiently differentiated ( $\theta$ is too close to 1$)$, parties start competing "à la Bertrand" by trying to steal all issues from their competitor. To represent this graphically, Figure 6 sets $\theta_{c}=0$, so that $q_{c}^{P}=0$ in any equilibrium. The point PSE represents the quality levels for party $A$ in the pure strategy equilibrium, and the point NISC the optimal quality for party $B$ in the same equilibrium. The latter point also represents the quality levels that party $A$ must surpass to steal all issues from party $B$, and thereby reach the area denoted " $\pi^{A}=1$ " at minimum cost: by Lemma 2 , locating just to the right of NISC dominates any other point in that area. The no-issue stealing condition is satisfied in Figure 6a, because the parties' reputation advantage is large $(\theta=3)$ and priming effects are moderate $(\beta=0.4)$. Heuristically, the points PSE and NISC are located sufficiently apart from one another. Deviating from PSE to NISC is then too costly: the pure strategy equilibrium exists and is the unique equilibrium. In Figure $6 \mathrm{~b}$, the parties' reputation advantage is small $(\theta=1.2 ; \beta$ is still 0.4). Thus, quality differentials are small in the pure strategy equilibrium, and issue stealing becomes cheap. In this case, there exists no PSE.

These graphs also shed some light on why the 2000 presidential election campaign in the US appears as an "outlier" in traditional issue ownership theories (see e.g. Petrocik et al. 2004). In that campaign, candidate G.W. Bush's single most 


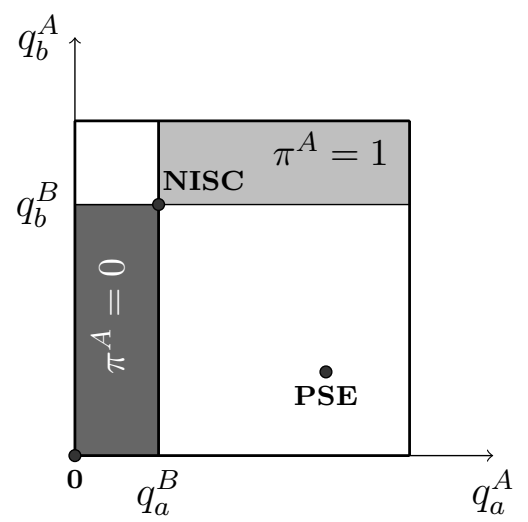

(a) $\theta=3$

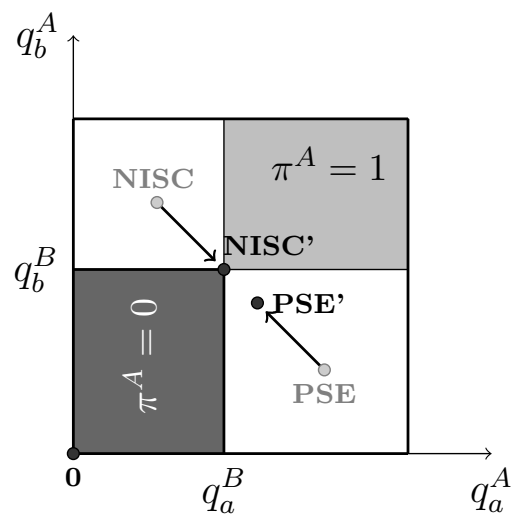

(b) $\theta=1.2$

Figure 6: In both panels, we fix $\theta_{c}=0$, so as to collapse one dimension, and $\beta=0.4$. In panel $a$, the reputation advantage is high, and deviations from the pure strategy equilibrium qualities (PSE) are too costly. In panel $b$, the reputation advantage is low and parties optimally deviate from PSE strategy.

advertised issue was "education", despite the Democratic Party's dominance on the issue since 1945. The magnitude of the Democratic advantage was very strong in 1996 (in October polls, NBC News and Gallup respectively identify a 23 and 29-point advantage for the democrats on that issue). By contrast, in 1999, that is prior to the beginning of the campaign, this advantage had fallen to $12 \%$. This corresponds to a shift from $\theta$ large in 1996 (Figure 6a) to $\theta$ small in 2000 (Figure 6b). Republicans thus had a chance to revert their handicap by engineering a new proposal, which is what Bush's No Child Left Behind proposal achieved. According to October 2000 Gallup Polls, $48 \%$ of the voters clearly supported Bush's proposals on education, against $44 \%$ for Gore. Accordingly, Bush campaigned more than Gore on education (Falk 2001 (p22) shows that Republicans aired 40\% more ads mentioning education than the Democrats).

Whenever the condition (11) is violated, there exists no equilibrium in pure strategy. Yet, the fact that payoffs are bounded and that payoff discontinuities are confined to a one-dimensional set of actions ensures equilibrium existence: 
Proposition 5 An equilibrium always exists. Hence, whenever condition (11) is violated, the equilibrium is in non-degenerate mixed strategies.

Proof. The first stage of our model features continuous payoffs almost everywhere: payoffs are continuous for any quality vectors $\mathbf{q}^{A} \neq \mathbf{q}^{B}$. Glicksberg (1952) proves equilibrium existence when payoffs are continuous. Hence, the question of equilibrium existence only arises because of discontinuities at the points in which $\mathbf{q}^{A}=\mathbf{q}^{B}$. To see this, fix $\hat{\mathbf{q}}^{B}=\left(\widehat{q}_{a}^{B}, \widehat{q}_{b}^{B}, \widehat{q}_{c}^{B}\right)$. For $\mathbf{q}^{A}=\hat{\mathbf{q}}^{B}$, we have $\Pi^{P}=\frac{1}{2}$, for $P \in\{A, B\}$. Yet, for any $\varepsilon>0$ and any issue $k$, a deviation towards $q_{k}^{A}=\widehat{q}_{k}^{B}-\varepsilon$, yields a winning probability of 0 (Case B). Conversely, a deviation towards $q_{k}^{A}=\widehat{q}_{k}^{B}+\varepsilon$, yields a winning probability of 1 (Case A). Dasgupta and Maskin (1986, Theorem 5b) and Simon (1987) show that an equilibrium necessarily exists in games with such payoff structures.

While fully characterizing this equilibrium in mixed strategies is beyond the scope of this paper, ${ }^{24}$ we can easily illustrate its main properties through a simpler, discrete, version of the model: consider the case of a discrete quality space, in which party $A$ can only choose one out of three quality levels:

$$
\mathbf{q}^{A} \in\left\{\mathbf{0}, \mathbf{q}^{A, P S E}, \mathbf{q}^{A, I S}\right\}
$$

which are respectively: invest 0 in all issues, at cost 0 ; invest the quality levels defined by the pure strategy equilibrium, at a cost which we denote $c_{L}$ for "low"; and steal all issues from party $B$, at a cost $c_{H}$ for "high". We have: $c_{H}>c_{L}>0$. Party $B$ has an equivalent choice set: $\mathbf{q}^{B} \in\left\{\mathbf{0}, \mathbf{q}^{B, P S E}, \mathbf{q}^{B, I S}\right\}$. The payoffs of party

\footnotetext{
${ }^{24}$ In their model, Kovenock and Roberson (2010) analyze a case in which parties compete on distinct districts, but effort/quality in one district does not directly influence the probability of victory in other districts. If we reinterpret their "districts" as "issues", their equilibrium shows that issue stealing must arise in their model. The main difference between their model and ours is that spillovers are present in our setup, making the characterization of the mixed strategy equilibrium intractable.
} 
$A$ for each combination of effort levels are as follows:

$$
\begin{array}{cccc} 
& \mathbf{0} & \mathbf{q}^{B, P S E} & \mathbf{q}^{B, I S} \\
\mathbf{0} & 1 / 2 & 0 & 0 \\
\mathbf{q}^{A, P S E} & 1-c_{L} & 1 / 2-c_{L} & -c_{L} \\
\mathbf{q}^{A, I S} & 1-c_{H} & 1-c_{H} & 1 / 2-c_{H}
\end{array}
$$

That is, if it provides zero quality, party $A$ wins with probability $1 / 2$ only if party $B$ also provides zero effort. Otherwise, it loses. If it provides the PSE quality levels, party $A$ entails cost $c_{L}$, and wins (a) with probability 1 if party $B$ plays $\mathbf{0}$, (b) with probability $1 / 2$ if $B$ provides the PSE qualities, and (c) with probability 0 if party $B$ steals issue $a$ from $A$. Finally, if $A$ plays $\mathbf{q}^{A, I S}$ to steal issue $b$, it entails $\operatorname{cost} c_{H}$. It wins with probability 1 if party $B$ either supplies 0 or PSE qualities, and with probability $1 / 2$ if party $B$ also engages in issue stealing.

In this simplified game, there is a unique pure strategy equilibrium in which $\left(\mathbf{q}^{A}, \mathbf{q}^{B}\right)=\left(\mathbf{q}^{A, P S E}, \mathbf{q}^{B, P S E}\right)$ if and only if: (1) $c_{L}<1 / 2<c_{H}$ and (2) the following equivalent to the no issue stealing condition holds:

$$
c_{L}<c_{H}-1 / 2
$$

Instead, when the latter condition is violated, we have:

Proposition 6 In the discrete-choice version of the model, whenever condition (12) is violated and for $0<c_{L}<1 / 2<c_{H}<1,{ }^{25}$ the equilibrium is unique and such

\footnotetext{
${ }^{25} c_{H}<1$ is a necessary condition for issue stealing to be profitable.
} 
that:

$$
\begin{gathered}
\operatorname{Pr}\left(\mathbf{q}^{A}=\mathbf{0}\right)=1-2\left(c_{H}-c_{L}\right)=\operatorname{Pr}\left(\mathbf{q}^{B}=\mathbf{0}\right) \\
\operatorname{Pr}\left(\mathbf{q}^{A}=\mathbf{q}^{A, P S E}\right)=2 c_{H}-1=\operatorname{Pr}\left(\mathbf{q}^{B}=\mathbf{q}^{B, P S E}\right) \\
\operatorname{Pr}\left(\mathbf{q}^{A}=\mathbf{q}^{A, I S}\right)=1-2 c_{L}=\operatorname{Pr}\left(\mathbf{q}^{B}=\mathbf{q}^{B, I S}\right)
\end{gathered}
$$

Hence, whenever condition (12) is violated, the equilibrium is in non-degenerate mixed strategies and implies issue stealing.

In words, if the cost of issue stealing is not too high -that is, when condition (12) is violated- there exists no pure strategy equilibrium. If party $B$ were to choose the PSE quality levels, party $A$ would prefer to engage in issue stealing, at the cost of higher investment in platform quality. Yet, party $B$ does not want to choose the PSE quality levels in that case: since it loses for sure, it would gain from cutting its investment costs and supplying 0-qualities in all issues. Next, if party $B$ sets 0-quality in all issues, party $A$ can still win with probability 1 by cutting down investment costs and selecting the PSE quality levels. In turn, if party $A$ chooses $\mathbf{q}^{A, P S E}$ with probability 1 , party $B$ prefers issue stealing, and so on. The unique equilibrium is thus in non-degenerate mixed strategies, implying that there is a strictly positive probability that either party steals all issues from the other.

Extending this logic to a continuous strategy space, whenever condition (11) is violated, both parties must strictly mix over quality levels, and may end up dominating the other party on any one, two or all issues with strictly positive probability. Thus, issue stealing (party $A$ offering higher quality than party $B$ on issue $b$ or conversely on issue $a$ ) happens with strictly positive probability and need not entail complete dominance by one party. 
The continuous version of the model also has the advantage of showing why and when condition (11) tends to be violated: the gap between $c_{L}$ and $c_{H}$ depends both on the parties' reputation advantages and on priming effectiveness. Strong reputation advantages reduce the $\operatorname{cost} c_{L}$ and increase the cost $c_{H}$, allowing for the pure strategy equilibrium to survive. Conversely, the two parties become indistinguishable when $\theta$ approaches 1 . In that case, $c_{L}$ and $c_{H}$ converge towards one another, which triggers issue stealing.

Yet, we also saw that the $\operatorname{cost} c_{L}$ must remain smaller than $1 / 2$ for either the PSE to exist or the deviation towards issue stealing to be profitable. Another effect of $\theta$ approaching 1 is that both costs increase. As we show in the next section, this increases the incentive to reduce platform quality.

\section{Effect of Priming on Competition}

We just studied the parties' temptation to deviate towards stealing all issues from each other. The second deviation to consider is whether party $A$ prefers to stop investing in its platform, and let party $B$ dominate on all issues. This also leads to issue stealing, although for the opposite reason: it is party $A$ 's decision to abandon issue $a$ to party $B$ that allows the latter to dominate.

When party $A$ reduces quality levels to 0 in all issues, it wins with probability

0 at cost 0 . Its payoff is thus nil. The temptation to deviate from $q^{A, P S E}$ to 0 is thus identical to checking the parties' participation constraint in the PSE. A second necessary condition for the pure strategy equilibrium to exist is that the payoff in (9) is positive, or:

Proposition 7 (Participation Constraint - PC) A necessary condition for the pure strategy equilibrium to exist is that comparative advantages $\theta$ be large and priming 
effectiveness $\beta$ be small: $\Pi^{P}\left(\mathbf{q}^{P S E}, \mathbf{t}\right) \geq 0$, iff

$$
\theta \geq \theta^{*}\left(\beta, \theta_{c}\right) \equiv \frac{5-3 \beta}{3-5 \beta}+\frac{4(1-\beta)^{2} \theta_{c}}{(1+\beta)(3-5 \beta)} \text { and } \beta<3 / 5
$$

Proposition 7 sheds a new light on the effects of priming on political competition. It shows that the overall effect of priming can work against the parties' objective of securing a safer position. Within the pure strategy equilibrium, higher priming effectiveness forces both parties to invest more in quality. This is the homogenization effect identified above. Party rents thus decrease and, by Proposition 7, the incentive to deviate from the PSE by pulling out of the race increases. Like in the previous case, since an equilibrium must exist, it must be in non-degenerate mixed strategies. ${ }^{26}$

Importantly, the incentive to pull out does not imply that competition gets soft in that equilibrium: if a party pulls out, the other party can dominate in all issues with very low policy qualities. In turn, this implies that the former party now also has an incentive to increase policy quality above its competitor's. This induces the other party to also increase quality, and so on up until the quality levels become so costly to reach that their participation constraint becomes binding.

Figure 7 illustrates the combined effects of the two conditions (11) and (13) when $\theta_{c}=0$. The two conditions are represented by the curves NISC and PC respectively. The PSE exists when comparative advantages are sufficiently large and priming effects are not too strong. Graphically, this is represented by the white area above both the NISC and PC curves, where $\theta$ is large and $\beta$ takes intermediate

\footnotetext{
${ }^{26}$ From the discrete choice space of the model described above, it is easy to identify how the mixed strategy equilibrium would be determined: imagine that the costs of supplying the PSE qualities are so high that it becomes dominated by $\mathbf{0}$. Then, there must exist two other quality effort levels strictly between $\mathbf{0}$ and PSE that satisfy the same conditions as in that simplified version of the model, and that produce the same mixture, with issue stealing.
} 


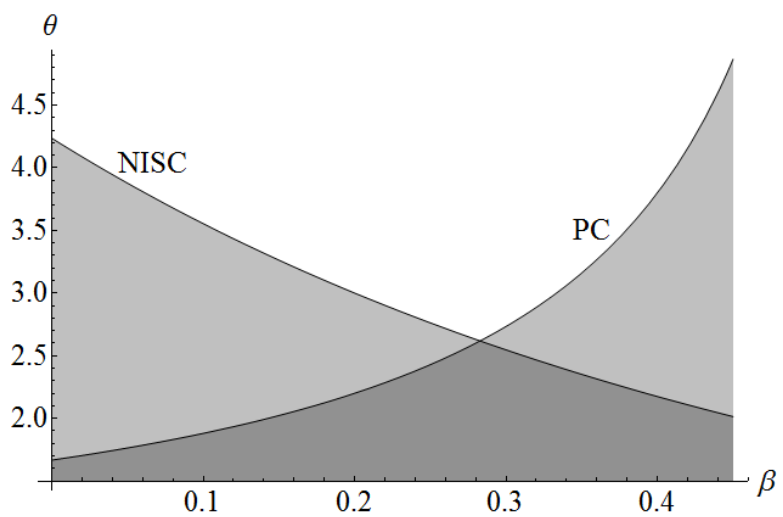

Figure 7: The NISC (No Issue Stealing Condition) and PC (participation constraint) when $\theta_{c}=0$

values. For such parameter values, parties are sufficiently differentiated (reputation advantages are large) to render issue stealing too costly, and parties do not need to invest lots of resources to ensure a $50 \%$ probability of winning, which ensures that their participation constraint is met. Competition is thus relatively soft in this area, leaving parties with strictly positive rents.

In the bottom left area of the graph, that is when party differences fade away (i.e. $\theta \rightarrow 1$ ) and priming effectiveness is sufficiently small, the temptation to engage in issue stealing becomes too strong for the pure strategy equilibrium to survive. As seen above, both parties then adopt a non-degenerate mixed strategy, which produces issue stealing with strictly positive probability. In the bottom-right area, the participation constraint is violated: the combination of low party differentiation and high priming effectiveness would force the two parties to engage in very costly investments to meet the PSE quality levels. They then also adopt a non-degenerate mixed strategy, again with the possibility of observing issue stealing.

Finally, the participation constraint shifts up when parties become abler at handling the unbiased issue (i.e. if $\theta_{c}$ increases). In other words, issue stealing should be more frequent when issues in which no party has a reputational advantage become 
more relevant in the political debate.

\section{Conclusions}

We proposed a model of endogenous issue ownership in which parties can compensate for a prior reputation disadvantage by investing in policy innovation. This contrasts with the standard approach on issue ownership: while lesser competence makes it costly to dominate on an issue, costs need not be prohibitive. Our contribution is precisely to identify under which circumstances a party chooses to maintain its reputational advantage and focus on its historically strong issues, or instead try to steal the opponent's issues.

We show that two parameters are central to distinguish these two cases: the magnitude of the initial reputation advantage and the effectiveness of the communication campaign. In contrast to common intuition, we find that elections become more competitive when the effectiveness of the communication campaign is higher, that is when priming has stronger influence on the voters. This is also when the incentive to engage in issue stealing increases. In other words, the parties' initial reputation (dis)advantage over each issue matters less when political advertisement becomes very effective. This result helps explain why issue ownership may have become less stable than traditionally perceived. Two additional and empirically testable results emerge from our analysis. First, the stronger is party reputation on key issues, the less competitive the election becomes, and the less likely is issue stealing. Second, stiff competition and issue stealing become more likely when parties face lower investment costs to providing innovative policies on "neutral" issues (issue $c$ in the model).

The relationships we identify between policy quality and the communication 
campaign also impact on voter welfare. Voter welfare is unambiguously increasing in policy quality. Yet, we found that more effective political advertisement affects policy quality differently across issues. For instance, in a pure strategy equilibrium, higher priming effectiveness leads to higher quality in the issues that are advertised, and lower quality in the muted issue. Welfare can thus be said to increase in priming effectiveness if quality is already close to zero for the muted issue. For the other cases, one must be cautious: the weighting rule that voters use when casting their ballot is manipulable and can thus not be treated as a welfare function. Similarly, in a mixed strategy equilibrium, realized qualities can be high or low, and which issues will be brought up during the campaign remains uncertain ex ante. Future research is thus needed to fully assess the welfare implications of such equilibrium behavior.

Note also that our model only focuses on valence issues: in our setup, voters only compare the relative quality of the two parties' proposals and vote for the platform with the highest weighted-average quality. This neglects ideology and issue divisiveness. We however want to argue that our approach (1) is robust to the introduction of some ideology in the voters' decision and (2) usefully complements the analysis of divisive issues by, e.g. Colomer and Llavador (2011), Glazer and Lohmann (1989), or Morelli and Van Weelden (2011, 2013).

We indeed could incorporate an ideological position attached to each voter and party. Introducing ideology would mean that the voters' tipping points in favor of one or another party would differ across voters, depending on the ideological distance between the party and their own bliss point. Thus, a party "dominating" on an issue would no longer swing all voters at once, but rather a fraction of the electorate that would be increasing smoothly in the quality advantage. In this way, 
a party's winning probability would increase steadily in its relative quality, and decrease in its ideological distance from the "average voter". On the one hand, this would make the analysis of mixed strategy equilibria simpler (since there would no longer be payoff discontinuities). In the spirit of the analyses by Krasa and Polborn (2010, 2014), it would also make it possible to analyze the question of why and when parties polarize, but this is beyond the scope of this paper. On the other hand, it would imply carrying over an additional expected ideological distance parameter (and its distribution) in all equations and conditions. Thus, while it would make the model a lot more realistic, this would be at the expense of substantial added complexity. In order to maintain the analysis simple, we have decided not to pursue this research line at this stage.

Regarding issue divisiveness, note that the above-referenced analyses do not study the feedback effects between the advertisement campaign and equilibrium platform quality. Clearly, a model that combines the intuitions of both approaches would be richer, but again at the expense of a significant increase in computational complexity. We also want to argue that divisive and valence issues coexist in electoral campaigns and target different audiences. Divisive issues are likely to affect more intensely the vote of partisan voters rather than independent voters. In contrast, swing voters and centrist voters are more sensitive to arguments about which policies will bring them a higher return. For instance: how to create more jobs? Which is the policy most likely to increase my disposable income? Which is the policy that will provide me with best protection against criminal activities? These swing voters are the ones we have in mind in our model, and we believe that our model is well suited to explain the sometimes significant electoral swings that are observed across elections. As our examples illustrate, many of these swings happened after a party 
acquired a "valence advantage" in some important issue. Interestingly, our model implicitly predicts that each voter will tend to remain more attached to a party if issue ownership remains stable across elections. The study of the relationship between partisanship and issue stealing is however left for future research.

Another potential avenue for future research is to go beyond the symmetric cases studied in this paper. Allowing for asymmetric comparative advantages for parties or a multiplication of issues would produce richer results. However, they would still stem from the same trade-offs as those identified in the symmetric case. Similarly, relaxing the assumption of a uniform distribution of the voters' initial issue salience might make equilibrium results fit additional stylized facts. For example, one could think that exogenous shocks increase or reduce the salience weight of some issues. Then, the campaign would again become asymmetric, depending on which party has a reputation advantage on the "shocked" issue.

Finally, the selection of issues during electoral campaigns also requires further research concerning the threat of entry by single-issue parties. This would provide a useful starting point to better analyze proportional elections. 


\section{Appendix}

Proof of Proposition 1: Consider the maximization problem for party $A$. In the second stage of the game, party $A$ 's FOCs are given by $\frac{\partial \Pi^{A}}{\partial t_{k}^{A}}=\frac{\partial \pi^{A}}{\partial t_{k}^{A}} \geq 0$ for $k \in\{a, b, c\}$. Maximizing the payoff is therefore equivalent to maximizing the probability of winning. Suppose that $\Delta_{a}>\Delta_{c}>\Delta_{c}$. In that case, the set of voters who cast their ballot for $A$ is given by (6). To maximize its probability of winning, $A$ must therefore increase $s_{a}^{i}\left(t_{a}\right)$ and reduce $s_{b}^{i}\left(t_{b}\right)$, which is achieved by focusing all its advertisement campaign on issue a, i.e. set $t_{a}^{A}=1 / 2$. Conversely, party $B$ should focus all its advertisement campaign on issue $b$, i.e. set $t_{b}^{B}=1 / 2$.

If instead $\Delta_{b}>\Delta_{a}>\Delta_{c}$, then party $A$ 's probability of winning is decreasing in $s_{a}^{i}\left(t_{a}\right)$ and increasing in $s_{b}^{i}\left(t_{b}\right)$. Hence, $A$ must focus all its advertisement campaign on issue $b$, i.e. set: $t_{b}^{A}=1 / 2$, whereas party $B$ should focus its campaign on issue $a$ and set $t_{a}^{B}=1 / 2$. Applying the same reasoning to all possible rankings of $\Delta_{a}, \Delta_{b}$, and $\Delta_{c}$ yields the proposition.

Proof of Proposition 2. Remember that the two parties' payoffs are respectively:

$$
\Pi^{A}\left(\mathbf{q}^{A}, \mathbf{q}^{B}, \mathbf{t}^{A}, \mathbf{t}^{B}\right)=\pi^{A}\left(\mathbf{q}^{A}, \mathbf{q}^{B}, \mathbf{t}^{A}, \mathbf{t}^{B}\right)-\sum_{k} \frac{\left(q_{k}^{A}\right)^{2}}{\theta_{k}^{A}},
$$

and:

$$
\Pi^{B}\left(\mathbf{q}^{A}, \mathbf{q}^{B}, \mathbf{t}^{A}, \mathbf{t}^{B}\right)=1-\pi^{A}\left(\mathbf{q}^{A}, \mathbf{q}^{B}, \mathbf{t}^{A}, \mathbf{t}^{B}\right)-\sum_{k} \frac{\left(q_{k}^{B}\right)^{2}}{\theta_{k}^{B}} .
$$

Moreover, $\theta_{a}^{A}=\theta_{b}^{B} \equiv \theta>1 \equiv \theta_{b}^{A}=\theta_{a}^{B}$ and $\theta_{c}^{A}=\theta_{c}^{B} \equiv \theta_{c}$. It follows that the parties' FOCs with respect to $q_{c}$ are: 


$$
\begin{aligned}
& \frac{d \Pi^{A}}{d q_{c}^{A}}=\frac{\partial \pi^{A}}{\partial \Delta_{c}} \cdot \frac{\partial \Delta_{c}}{\partial q_{c}^{A}}-2 \frac{q_{c}^{A}}{\theta_{c}}=\frac{\partial \pi^{A}}{\partial \Delta_{c}}-2 \frac{q_{c}^{A}}{\theta_{c}}=0, \\
& \frac{d \Pi^{B}}{d q_{c}^{B}}=\frac{\partial \pi^{B}}{\partial \Delta_{c}} \cdot \frac{\partial \Delta_{c}}{\partial q_{c}^{B}}-2 \frac{q_{c}^{B}}{\theta_{a}^{B}}=-\frac{\partial \pi^{A}}{\partial \Delta_{c}}(-1)-2 \frac{q_{c}^{B}}{\theta_{c}}=0 .
\end{aligned}
$$

Thus, in equilibrium, $q_{c}^{A^{*}}=q_{c}^{B^{*}}=\frac{\theta_{c}}{2} \frac{\partial \pi^{A}}{\partial \Delta_{c}}$, which implies $\Delta_{c} \equiv q_{c}^{A}-q_{c}^{B}=0$.

Similarly, the parties' FOCs with respect to $q_{a}$ are:

$$
\begin{aligned}
& \frac{d \Pi^{A}}{d q_{a}^{A}}=\frac{\partial \pi^{A}}{\partial \Delta_{a}} \cdot \frac{\partial \Delta_{a}}{\partial q_{a}^{A}}-2 \frac{q_{a}^{A}}{\theta}=\frac{\partial \pi^{A}}{\partial \Delta_{a}}-2 \frac{q_{a}^{A}}{\theta}=0, \\
& \frac{d \Pi^{B}}{d q_{a}^{B}}=\frac{\partial \pi^{B}}{\partial \Delta_{a}} \cdot \frac{\partial \Delta_{a}}{\partial q_{a}^{B}}-2 q_{a}^{B}=-\frac{\partial \pi^{A}}{\partial \Delta_{a}}(-1)-2 q_{a}^{B}=0 .
\end{aligned}
$$

Thus, in equilibrium, $q_{a}^{A^{*}}=\frac{\theta}{2} \frac{\partial \pi^{A}}{\partial \Delta_{a}}$ and $q_{a}^{B^{*}}=\frac{1}{2} \frac{\partial \pi^{A}}{\partial \Delta_{a}}$, which implies $q_{a}^{A^{*}} / q_{a}^{B^{*}}=\theta$. Recall that $\theta>1$. Hence, $\Delta_{a} \equiv q_{a}^{A^{*}}-q_{a}^{B^{*}}=(\theta-1) q_{a}^{B^{*}}>0$. Applying similar calculations to $q_{b}$ obtains $q_{b}^{B^{*}}=\frac{1}{2} \frac{\partial \pi^{A}}{\partial \Delta_{b}}$ and $q_{b}^{B^{*}}=\frac{\theta}{2} \frac{\partial \pi^{A}}{\partial \Delta_{b}}$. Therefore, $q_{b}^{B^{*}} / q_{b}^{A^{*}}=\theta$ and $\Delta_{b} \equiv q_{b}^{A^{*}}-q_{b}^{B^{*}}=$ $(1-\theta) q_{a}^{B^{*}}<0$.

\section{Lemma A1.}

Let:

$$
\alpha \equiv \frac{\Delta_{c}-\Delta_{b}}{\Delta_{a}-\Delta_{c}}(>0) \text { and } \gamma \equiv-\frac{\Delta_{c}}{\Delta_{a}-\Delta_{c}}
$$


The parties' winning probabilities can then be written as:

$$
\pi^{A}\left(q^{A}, q^{B}, q^{C} ; t^{A}, t^{B}\right)=\left\{\begin{array}{c}
1 \text { if } \gamma+\alpha \beta t_{b} \leq \beta t_{a}-\alpha(1-\beta) \\
1-\frac{\left[\alpha(1-\beta)+\gamma+\beta\left(\alpha t_{b}-t_{a}\right)\right]^{2}}{\alpha(1+\alpha)(1-\beta)^{2}} \\
\text { if } \beta t_{a}-\alpha(1-\beta) \leq \gamma+\alpha \beta t_{b} \leq \beta t_{a} \\
\frac{\left[(1-\beta)-\gamma+\beta\left(\alpha t_{a}-t_{b}\right)\right]^{2}}{(1+\alpha)(1-\beta)^{2}} \\
\text { if } \beta t_{a} \leq \gamma+\alpha \beta t_{b} \leq \beta t_{a}+1-\beta \\
0 \text { if } \gamma+\alpha \beta t_{b} \geq \beta t_{a}+1-\beta \\
\pi^{B}\left(q^{A}, q^{B}, q^{C} ; t^{A}, t^{B}\right)=1-\pi^{A}\left(q^{A}, q^{B}, q^{C} ; t^{A}, t^{B}\right)
\end{array}\right.
$$

Proof. Using (2) and Proposition 2, the pivotal voter will vote for $A$ at stage 3 if her weighting of issue $a$, denoted $s_{a}^{i}$, is higher than the value defined by the separating line:

$$
s_{a}\left(t_{a}\right)=s_{b}\left(t_{b}\right) \alpha+\gamma
$$

In this proof, we focus on the case in which $\gamma+\alpha \beta t_{b} \leq \beta t_{a}$, which is depicted in Figure 8. We also impose that $\gamma+\alpha \beta t_{b}$ is sufficiently large, such that $\pi^{B}(\cdot)$ is strictly positive. Graphically, these conditions imply that the separating line cuts the simplex "from below". $B$ 's winning probability is then the (strictly positive) mass of points with $s_{a}\left(t_{a}\right) \leq \gamma+$ $\alpha s_{b}\left(t_{b}\right)$. Knowing that, within the simplex $S_{s}(\mathbf{t}, \beta)$, the density is $2 /(1-\beta)^{2}, B$ 's winning probability is defined by:

$$
\pi^{B}\left(q^{A}, q^{B}, q^{C} ; t^{A}, t^{B}\right)=\int_{\beta t_{a}}^{s_{a}^{1}} \int_{\frac{s_{a}-\gamma}{\alpha}}^{K-s_{a}} \frac{2}{(1-\beta)^{2}} d s_{b} d s_{a}
$$

where: $K \equiv \beta\left(t_{a}+t_{b}\right)+(1-\beta)$ is origin of the downward sloping line $s_{a}=K-s_{b}$ in Figure 8 and $s_{a}^{1} \equiv \frac{\alpha K+\gamma}{1+\alpha}$ is the value of $s_{a}$ at the point of intersection between that line and the separating line (16). Remark also that $s_{b} \equiv \frac{s_{a}-\gamma}{\alpha}$ is the inverse of the separating 


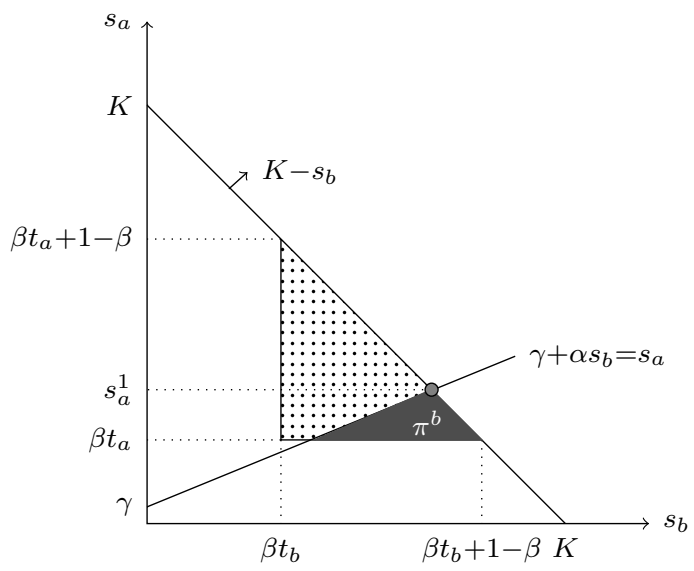

Figure 8: The winning probability of $B$ is given by the black area.

line. This integral represents the surface of the triangle $\pi^{B}$ in Figure 8, multiplied by the density of the population within the simplex.

Substituting for $K$ and $s_{a}^{1}$ in (17) and executing the integral yields:

$$
\pi^{B}(\cdot)=\frac{\left[\alpha(1-\beta)+\gamma+\beta\left(\alpha t_{b}-t_{a}\right)\right]^{2}}{\alpha(1+\alpha)(1-\beta)^{2}} .
$$

The second value of $\pi^{A}(\cdot)$ in (15) is simply $1-\pi^{B}(\cdot)$. The first, third, and fourth cases in (15) are the values of $\pi^{A}(\cdot)$ when the separating line respectively $(i)$ passes entirely to the right of the simplex, (ii) cuts the simplex "from the left" and (iii) passes entirely above the simplex.

Proof of Lemma 1: To prove the lemma, we use the winning probabilities that result from Lemma A1 (see above in this appendix) when $t_{k}=1 / 3, \forall k \in\{a, b, c\}$, solve for the equilibrium quality levels that would result, differentiate them with respect to $\beta$.

Focusing on the same case as in Lemma A1, we have:

$$
\pi_{B}\left(q^{A}, q^{B}, q^{C} ; \frac{1}{3}, \frac{1}{3}\right)=\frac{[\alpha(1-\beta)+\gamma+\beta(\alpha-1) / 3]^{2}}{\alpha(1+\alpha)(1-\beta)^{2}}
$$

The first order conditions defining the optimal levels of quality are therefore: $\frac{\partial \pi_{P}}{\partial \alpha} \frac{\partial \alpha}{\partial q_{k}^{P}}+$ 
$\frac{\partial \pi_{P}}{\partial \gamma} \frac{\partial \gamma}{\partial q_{k}^{P}}=\frac{2 q_{k}^{P}}{\theta_{k}}$, where $\frac{\partial \pi_{A}}{\partial x}=-\frac{\partial \pi_{B}}{\partial x}$ for $x=\alpha, \gamma$. Differentiating (19) yields:

$$
\begin{aligned}
\frac{\partial \pi_{B}}{\partial \alpha} & =\frac{\left(1-\frac{2}{3} \beta\right)(1-2 \gamma)-(1+2 \alpha)\left(\frac{\beta / 3-\gamma}{\alpha}\right)^{2}}{(1+\alpha)^{2}(1-\beta)^{2}}, \text { and } \\
\frac{\partial \pi_{B}}{\partial \gamma} & =\frac{\alpha+\gamma-\frac{\beta(1+2 \alpha)}{3}}{\alpha(1+\alpha)(1-\beta)^{2}}
\end{aligned}
$$

Differentiating $\alpha$ and $\gamma$ and substituting, we find that in equilibrium, $q_{b}^{A}$ must be equal to $q_{a}^{B}$, and hence that $\alpha=1$. From Proposition 2, we also have that $\gamma=0$. After some manipulations, this yields:

$$
q_{a}^{A} / \theta=q_{a}^{B}=\sqrt{\frac{4-(1+\beta)^{2}}{24(1-\beta)^{2}(\theta-1)}}=q_{b}^{B} / \theta=q_{b}^{A} .
$$

This implies:

$$
\frac{\partial q_{b}^{A}}{\partial \beta}=\left((1-\beta) \sqrt{6(\theta-1)\left(4-(1+\beta)^{2}\right)}\right)^{-1}>0 .
$$

Next, we have:

$$
q_{c}^{A}=\frac{2 \theta_{c}}{\sqrt{6} \sqrt{\theta-1}} \frac{\beta^{2}-4 \beta+3}{(1-\beta) \sqrt{3-2 \beta-\beta^{2}}} .
$$

Differentiating and simplifying:

$$
\frac{\partial q_{c}^{A}}{\partial \beta}=\frac{8 \beta \theta_{c}}{\sqrt{6} \sqrt{\theta-1}\left(3-2 \beta-\beta^{2}\right)^{3 / 2}}>0
$$

Proof of Proposition 3: To prove the proposition, we use the winning probabilities that result from Lemma A1 (see above in this appendix) when $t_{a}=t_{b}=1 / 2$, and $t_{c}=0$. Using the same reference case as in the proofs of Lemmas 1 and A1, we have:

$$
\pi^{B}\left(\mathbf{q}^{A}, \mathbf{q}^{B} ; \frac{1}{2}, \frac{1}{2}\right)=\frac{[\alpha(1-\beta)+\gamma+\beta(\alpha-1) / 2]^{2}}{\alpha(1+\alpha)(1-\beta)^{2}} .
$$

Note that the only difference between (21) and (19) in the proof of Lemma 1 is that the last term in the numerator is divided by 2 instead of 3 . Derivations are thus similar 
and imply again that $\alpha=1$ and $\gamma=0$. In other words, any pure strategy equilibrium must be symmetric and such that: $q_{a}^{A} / \theta=q_{a}^{B}=q_{b}^{B} / \theta=q_{b}^{A}$.

Using the equilibrium values of $\alpha$ and $\gamma$ to simplify $\frac{\partial \pi^{A}}{\partial \alpha}$ and $\frac{\partial \pi^{A}}{\partial \gamma}$ yields:

$$
\frac{\partial \pi^{A}}{\partial \alpha}=-\frac{1+\beta}{4(1-\beta)}
$$

and

$$
\frac{\partial \pi^{A}}{\partial \gamma}=-\frac{1}{1-\beta}
$$

The proposition follows from substituting these values into the FOCs and finding that the solution is unique.

Now, we prove two Lemmas that show that we only need to consider one specific deviation towards Case A or Case B. The first Lemma focuses on Case A:

Lemma 2 Conditional on party $A$ uniformly dominating party $B\left(\min _{k} \Delta_{k} \geq 0\right)$, party $A$ maximizes its objective function by setting $q_{a}^{A}=q_{a}^{B}+\varepsilon_{a}, q_{b}^{A}=q_{b}^{B}$ and $q_{c}^{A}=q_{c}^{B}+\varepsilon_{c}$, with $\varepsilon_{a}, \varepsilon_{c} \geq 0$ and $\varepsilon_{a} \varepsilon_{c}=0$.

Proof. For any $\left\{q_{a}^{A}, q_{b}^{A}, q_{c}^{A}\right\}$ such that $\min _{k} \Delta_{k} \geq 0$, the winning probability of party $A$ is 1 . Therefore, party $A$ can only increase its payoff by reducing quality provision, subject to $\min _{k} \Delta_{k} \geq 0$ and at least one $\Delta_{k}>0$.

The next lemma establishes that we only need to consider one potential deviation towards Case B:

Lemma 3 Conditional on party $B$ uniformly dominating party $A\left(\max _{k} \Delta_{k} \leq 0\right)$, party $A$ maximizes its objective function by setting $q_{a}^{A}=q_{b}^{A}=q_{c}^{A}=0$.

Proof. Party A's winning probability is always 0 in this case B. Cost minimization yields the result.

Proof of Proposition 5: The first stage of our model features continuous payoffs almost everywhere: payoffs are continuous for any quality vectors $\mathbf{q}^{A} \neq \mathbf{q}^{B}$. Glicksberg 
(1952) proves equilibrium existence when payoffs are continuous. Hence, the question of equilibrium existence only arises because of discontinuities at the points in which $\mathbf{q}^{A}=\mathbf{q}^{B}$. To see this, fix $\hat{\mathbf{q}}^{B}=\left(\widehat{q}_{a}^{B}, \widehat{q}_{b}^{B}, \widehat{q}_{c}^{B}\right)$. For $\mathbf{q}^{A}=\hat{\mathbf{q}}^{B}$, we have $\Pi^{P}=\frac{1}{2}$, for $P \in\{A, B\}$. Yet, for any $\varepsilon>0$ and any issue $k$, if $q_{k}^{A}=\widehat{q}_{k}^{B}-\varepsilon$ whereas the other qualities $q_{j}^{A}$ remain unchanged, we are in Case $\mathbf{B}$ and we have $\Pi^{A}=0$. Conversely, if $q_{k}^{A}=\widehat{q}_{k}^{B}+\varepsilon$ whereas the other qualities $q_{j}^{A}$ remain unchanged, we are in Case $\mathbf{A}$, and we have $\Pi^{A}=1$. This situation is identical to that of an all pay auction, in which auctioneers sink a bidding cost (here: $\left.C^{P}\left(\mathbf{q}^{P}\right)\right)$ before the auction, and the bidder with the highest bid wins the auction. Baye, Kovenock, and de Vries (1996) prove that an equilibrium must exist in such games.

Proof of Proposition 7: The participation constraint is violated if $\Pi^{A}(\mathbf{P S E})<0$. From (9), this imposes that:

$$
\frac{1}{2}-\frac{1+\beta}{1-\beta} \frac{\theta+1}{8(\theta-1)}-\frac{1-\beta}{1+\beta} \frac{\theta_{c}}{2(\theta-1)}<0
$$

After some manipulations, this yields:

$$
\theta(3-5 \beta)<5-3 \beta+4 \frac{(1-\beta)^{2}}{(1+\beta)} \theta_{c}
$$

This inequality always holds for $\beta \geq \frac{3}{5}$. Conversely, for $\beta<\frac{3}{5}$, simplifying (24) yields Proposition 7.

Differentiating the condition with respect to $\beta$ shows that $\theta^{*}\left(\beta, \theta_{c}\right)$, which is the lowest level of $\theta$ compatible with the PSE, is increasing in $\beta$ if either $\beta>1 / 3$ or $\theta_{c}<\frac{(1+\beta)^{2}}{(1-\beta)(1-3 \beta)}$. Under these conditions, issue stealing is more likely the higher is priming effectiveness 


\section{References}

Aldrich, John H., Griffin, John D. and Jill Rickershauser. 2005. "The Presidency and the Campaign: Altering Voter Priorities in the 2004 Election." In The Presidency and the Political System. Washington DC: Congressional Quarterly.

Amorós, Pablo and M. Socorro Puy. 2013. "Issue-Convergence or Issue-Divergence in the Political Campaign?" Public Choice 155(3-4): 355-71.

Ansolabehere, Stephen and Shanto Iyengar. 1994. "Riding the Wave and Claiming Ownership over Issues: the Joint Effects of Advertising and News Coverage in Campaigns." Public Opinion Quarterly 58(3): 335-357.

Aragonès, Enriqueta and Santiago Sánchez-Pagés. 2011. "The Disadvantage of Winning an Election." UFAE and IAE working paper 811.10.

Bartels, Larry M. 1996. "Politicians and the Press: Who Leads, Who Follows?" Presented at the Annual Meeting of the American Political Science Association, San Francisco, September 1996.

Bartels, Larry M. 2006. "Priming and Persuasion in Presidential Campaigns." In Capturing Campaign Effects. Ann Arbor: University of Michigan Press, 78-112.

Bélanger, Éric and Bonnie M. Meguid. 2008. "Issue Salience, Issue Ownership, and IssueBased Vote Choice." Electoral Studies 27: 477-491.

Brandenburg, Heinz. 2002. "Who Follows Whom? Investigating Agenda Dynamics between Parties and the Media over the Course of an Electoral Campaign." Harvard International Journal of Press/Politics 7(3): 34-54.

Cohen, Bernard C. 1963. The Press and Foreign Policy. Princeton, NJ: Princeton University Press. 
Colomer, Josef M. and Humberto Llavador. 2011. "An Agenda-Setting Model of Electoral Competition." Journal of the Spanish Economic Association 3(1): 73-93.

Damore, David F. 2004. "The Dynamics of Issue Ownership in Presidential Campaigns." Political Research Quarterly 57(3): 391-397.

Dasgupta, Partha and Eric Maskin. 1986. "The Existence of Equilibrium in Discontinuous Economic Games, I: Theory." Review of Economic Studies 53(1): 1-26.

Demange, Gabrielle and Karine Van Der Straeten. 2013. "Communicating on Electoral Platforms." PSE and TSE mimeo.

Egorov, Georgy. 2012. "Single-Issue Campaigns and Multidimensional Politics." Northwestern University, mimeo.

Falk, Erika 2001. "Content and Tenor of Issue Ads." In Issue Advertising in the 19992000 Election Cycle, ed. Kathleen Hall Jamieson. Annenberg Public Policy Center of the University of Pennsylvania, 20-22.

Glazer, Amihai and Lohmann, Susanne. 1999. "Setting the Agenda: Electoral Competition, Commitment of Policy, and Issue Salience." Public Choice 99(3-4): 377-94.

Holian, David B. 2004. "He's Stealing My Issues! Clinton's Crime Rhetoric and the Dynamics of Issue Ownership." Political Behavior 26(2): 95-124.

Iyengar, Shanto. 1990. "The Accessibility Bias in Politics: Television News and Public Opinion." International Journal of Public Opinion Research 2: 1-15.

Iyengar, Shanto and Donald R. Kinder. 1987. News that matters: Television and American Opinion. Chicago: University of Chicago Press.

Iyengar, Shanto, Donald R. Kinder and Mark D. Peters. 1982. "Experimental Demonstrations of the 'Not-So-Minimal' Consequences of Television News Programs." American Political Science Review 76(4): 848-858. 
Iyengar, Shanto and Nicholas A. Valentino. 2000. "Who says What? Source Credibility as a Mediator of Campaign Advertising" In Elements of Reason: Cognition, Choice, and the Bounds of Rationality, eds. Arthur Lupia, Mathew D. McCubbins and Samuel L. Popkin. Cambridge: Cambridge University Press.

Kahneman, Daniel and Amos Tversky. 1979. "Prospect Theory: An Analysis of Decision under Risk." Econometrica 47(2): 263-291.

Kahneman, Daniel and Amos Tversky. 1981. "The Framing of Decisions and the Psychology of Choice." Science 211(4481): 453-458.

Kahneman, Daniel and Amos Tversky. 1984. "Choices, Values and Frames." American Psychologist 39(4): 341-350.

Kovenock, Dan and Brian Roberson. 2010. "Conflicts with Multiple Battlefields." In $O x$ ford Handbook of the Economics of Peace and Conflict, eds. Michelle R. Garfinkel and Stergios Skaperdas. New York: Oxford University Press, 503-531.

Krasa, Stefan and Matias Polborn. 2010. "Competition between Specialized Candidates." American Political Science Review 104(4): 745-765.

Krasa, Stefan and Matias Polborn. 2014. "Social Ideology and Taxes in a Differentiated Candidates Framework." American Economic Review 104(1): 308-22.

Krosnick, Jon A. and Donald R. Kinder. 1990. "Altering the Foundations of Support for the President through Priming." American Political Science Review 84(2): 497-512.

Lenz, Gabriel S. 2009. "Learning and Opinion Change, not Priming: Reconsidering the Priming Hypothesis." American Journal of Political Science 53(4): 821-837.

McCombs, Maxwell E. and Donald L. Shaw. 1972. "The Agenda-Setting Function of Mass Media." Public Opinion Quarterly 36(2):176-187. 
Morelli, Massimo and Richard Van Weelden. 2011. "Re-election Through Division." mimeo, Columbia University.

Morelli, Massimo and Richard Van Weelden. 2013. "Ideology and Information in Policymaking." Journal of Theoretical Politics 25(3): 412-39.

Page, Benjamin I. and. Robert Y. Shapiro. The Rational Public. Chicago: University of Chicago Press.

Petrocik, John R. 1996. "Issue Ownership in Presidential Elections, with a 1980 Case Study." American Journal of Political Science 40(3): 825-850.

Petrocik, John R., William L. Benoit and Glenn J. Hansen. 2004. "Issue Ownership and Presidential Campaigning, 1952-2000.” Political Science Quarterly 118(4): 599-626.

Pope, Jeremy C. and Jonathan Wonn. 2009. "Measuring Changes in American Party Reputations, 1939-2004.' ' Political Research Quarterly 62(4): 653-661.

Riker, William H. 1993. Agenda Formation. Ann Arbor: University of Michigan press.

Sheafer, Tamir and Weimann, Gabriel 2005. "Agenda Building, Agenda Setting, Priming, Individual Voting Intentions, and the Aggregate Results: An Analysis of Four Israeli Elections." Journal of Communication 55(2): 347-365.

Sides, John. 2006. "The Origins of Campaign Agendas." British Journal of Political Science 37(3): 477-504.

Sigelman, Lee and Emmett H. Buell, Jr. 2004. "Avoidance or Engagement? Issue Convergence in U.S. Presidential Campaigns, 1960-2000." American Journal of Political Science 48(4): $650-661$.

Simon, Leo. 1987. "Games with Discontinuous Payoffs." The Review of Economic Studies 54(4): 569-97. 
Slass, Lorie. 2001. "Spending on Issue Ads", in Issue Advertising in the 1999-2000 Election Cycle, ed. Kathleen Jamieson, Annenberg Public Policy Center of the University of Pennsylvania, 4-10.

Smith, Tom W. 1985a. "The Polls: America's Most Important Problems, Part I: National and International." Public Opinion Quarterly 49(2): 264-74.

Smith, Tom W. 1985b. "The Polls: America's Most Important Problems, Part II: Regional, Community, and Personal." Public Opinion Quarterly 49(3): 403-10.

Soubeyran, Raphael and Pascal Gautier. 2008. "”Political Cycles: Issue Ownership and the Opposition Advantage." Journal of Public Economic Theory 10(4): 685-716.

Walgrave, Stefaan, Jonas Lefevere and Michiel Nuytemans. 2009. "Issue Ownership Stability and Change: How Political Parties Claim and Maintain Issues through Media Appearances." Political Communication 26(2): 153-172. 


\section{Supporting information (online supplementary ma- terial)}

This supplementary appendix shows how the modeling assumption that the two parties have equal campaigning times should actually be seen as a natural outcome when parties can decide how much budget to spend on advertising.

To this end, consider the following extension of the model: each party chooses how many ads to buy. The price $p$ of an advert is determined by the law of supply and demand. It is therefore identical for the two parties, and it is increasing in the total demand for adverts.

Parties would then maximize the following objective function:

$$
\Pi^{P}(\mathbf{q}, \mathbf{t})=V^{P}(\mathbf{q}, \mathbf{t})-C^{P}-p \times \sum_{k} t_{k}^{P} .
$$

In this extended setup, total campaigning time is endogenous. In contrast, we normalized this total time to 1 in the base model. We endogenous campaigning time, we need to adapt the priming function:

$$
s_{k}^{i}=\beta \frac{t_{k}}{\sum_{k} t_{k}}+(1-\beta) \sigma_{k}^{i} .
$$

In this way, $\beta$ remains the relative influence of the electoral campaign. The necessary first order condition to maximize $(25)$ with respect to $t_{k}$ is now:

$$
\frac{d V^{P}(\mathbf{q}, \mathbf{t})}{d t_{k}}=p .
$$

That is, the marginal benefit in terms of vote share should be equalized to the marginal cost of a campaigning advert, $p$. This marginal benefit depends on how one additional minute of campaigning time on issue $k$ affects issue weights:

$$
\frac{d s_{k}^{i}}{d t_{k}}=\beta \frac{1}{\sum_{k} t_{k}}\left(1-\frac{t_{k}}{\sum_{k} t_{k}}\right)
$$

which is decreasing in $t_{k}$. Thus, the marginal influence of campaigning time is decreasing 
in a party's campaigning time, and increasing in the other party's campaigning time. Factoring in the fact that the two parties have a symmetric impact on issue weights, it is straightforward to see that the unique equilibrium is for the two parties to equalize their campaigning times. This is true for any set of quality differentials: if, say party $A$ has a larger advantage on $a$ than $B$ has on $b$, the marginal benefit of emphasizing issue $a$ is large. But then, the benefit of bringing up issue $b$ is large as well. Thus, the only case in which parties would have a different advertisement strategy is when their funding costs or their budget constraints are different. 